\title{
Caracterização geoquímica e estrutural do Granodiorito Cruzeiro do Sul: magmatismo shoshonítico pós-colisional neoproterozoico em zona de transcorrência, região de Quitéria, RS
}

\author{
Geochemical and structural characterization of the Cruzeiro do Sul Granodiorite: \\ neoproterozoic post-collisional shoshonitic magmatism within transcurrent shear zone, \\ Quitéria region, Southernmost Brazil
}

\author{
Daniel Knijnik ${ }^{1}$, Maria de Fátima Bitencourt ${ }^{1}$, Lauro V. S. Nardi ${ }^{1}$, Viter Magalhães Pinto ${ }^{2}$, Eduardo Fontana ${ }^{1}$ \\ ${ }^{1}$ Instituto de Geociências - Campus do Vale - Universidade Federal do Rio Grande do Sul - UFRGS, Avenida Bento Gonçalves \\ 9.500, Caixa Postal 15001, CEP 91500-000, Porto Alegre, RS, BR (daniel_bk@live.com.au), (fatimab@ufrgs.br), \\ (lauro.nardi@ufrgs.br), (eduardo.fontana@ufrgs.br) \\ ${ }^{2}$ Universidade Federal de Sergipe - UFS, Aracaju, SE, BR (viter.pinto@gmail.com)
}

Recebido em 10 de março de 2011; aceito em 24 de janeiro de 2012

\begin{abstract}
Resumo
O Granodiorito Cruzeiro do Sul localiza-se na porção leste do escudo Sul-rio-grandense e ocorre como um corpo de aproximadamente $4 \mathrm{~km}^{2}$, alongado na direção ENE-WSW, controlado por uma zona de cisalhamento transcorrente sinistral. Esta unidade foi desmembrada do Complexo Arroio dos Ratos por constituir corpos mapeáveis intrusivos no mesmo, que preservam suas características primárias. Este granitoide compreende hornblenda-biotita granodioritos ricos em máficos (M’ 20), possui foliação magmática marcada pelo alinhamento dimensional dos feldspatos e minerais máficos, com um importante componente milonítico, principalmente próximo aos contatos. Veios leucograníticos concordantes e discordantes são comuns e, em zonas de mais alta deformação, geram um bandamento composto juntamente com enclaves microgranulares máficos alongados e diques sinplutônicos de composição diorítica a tonalítica paralelos à foliação. A foliação milonítica é paralela à primária, com direção EW a ENE-WSW e médio a alto ângulo de mergulho, contendo lineação de estiramento de baixo caimento para W e WSW, indicando-se a cinemática transcorrente da zona de cisalhamento. O sentido de movimento sinistral desta zona é confirmado por diversos indicadores cinemáticos de escalas meso e microscópica, e as microestruturas desenvolvidas sobre os feldspatos indicam temperaturas de deformação compatíveis com as da fácies anfibolito. A forma alongada dos corpos paralelamente à zona de transcorrência, a concordância e a progressão da foliação magmática em relação à milonítica, ambas paralelas aos limites das intrusões, são evidências estruturais de seu caráter sintectônico. Por outro lado, a ausência de foliação metamórfica retrabalhada pela milonítica permite concluir que o granitoide estudado registra apenas uma fase de deformação, que teria ocorrido durante o seu posicionamento, descartando sua relação com o evento transversal de direção EW e baixo ângulo de mergulho responsável pela deformação do Complexo Arroio dos Ratos e vinculando-o ao evento de transcorrência da Zona de Cisalhamento Dorsal de Canguçu. As características composicionais são consistentes com o caráter pós-colisional do magmatismo, e a afinidade shoshonítica é revelada pelos altos teores de $\mathrm{Sr}$, pelo comportamento linear e homogêneo dos elementos terras raras e pela abundância dos elementos terras raras leves em relação aos elementos terras raras pesados. Os padrões de elementos traço, com enriquecimento em $\mathrm{Ba}$ e Rb e empobrecimento dos HFS (High Field Strength Elements) em relação aos LILE (Large Ion Lithophile Elements), bem como seu caráter metaluminoso, também são importantes características que marcam sua afinidade shoshonítica. As condições de P e T, calculadas a partir do geobarômetro Alt-Hb e do termobarômetro Plg-Hb, são estimadas em cerca de 4,3 a 5,3 kbars e temperaturas de cristalização na ordem de 720 a $760^{\circ} \mathrm{C}$.
\end{abstract}

Palavras-chave: Zona de cisalhamento dorsal de Canguçu; Ambiente pós-colisional; Magmatismo sintectônico; Série shoshonítica. 


\begin{abstract}
The Cruzeiro do Sul Granodiorite is located in the Eastern portion of the Sul-rio-grandense shield. It forms one ENE-WSW elongate body of approximately $4 \mathrm{~km}^{2}$ within a sinistral strike slip shear zone. The rocks were originally considered as part of the Arroio dos Ratos Complex, but they were recently mapped as a separate unit because igneous textures are widely preserved and they are intrusive in the gneissis complex rocks. The Cruzeiro do Sul Granodiorite is thus a porphyritic horblende-biotite granodiorite in a mafic-rich (M' 20), medium-grained matrix. The magmatic foliation is marked by the shape alignment of feldspar megacrystals and mafic minerals. A solid-state, mylonitic structure is well-developed mainly near the contacts. Leucocratic veins are found both concordant and discordant to the main foliation, and they may give rise to a composite banding within high-strain zones, together with elongate mafic microgranular enclaves and synplutonic dykes of tonalitic to dioritic composition. The mylonitic foliation trends EW to ENE-WSW with medium to steep dip, and contains a shallow plunging stretching lineation, which indicates a transcurrent kinematic for this shear zone. Structural evidences, such as the parallelism and progressive evolution of mylonitic foliation relative to the magmatic one, as well as the elongated form of granodioritic bodies and the concordant character of planar structures with the ENE shear zone, are interpreted as an indication of syntectonic emplacement. Moreover, the absence of metamorphic foliation reworked by mylonitic shows that the Cruzeiro do Sul Granodiorite registers only one phase of deformation, which would have occurred during their emplacement. Thus, we have concluded that the Cruzeiro do Sul Granodiorite has no relation with the EW transversal event, and low dip angle responsible for the deformation of Arroio dos Ratos Complex, but is linked to the transcurrent event of Dorsal de Canguçu Shear Zone. The structural and compositional features of Cruzeiro do Sul Granodiorite magmatism are consistent with its post-collisional character, and the shoshonitic affinity is given by its high $\mathrm{Sr}$ contents, regular rare earth element chondrite-normalized patterns and the abundance of light rare earth regarding the heavy rare earth elements. Patterns of trace elements with enrichment in $\mathrm{Ba}$ and $\mathrm{Rb}$, and impoverishment of High-Field Strength in relation to Large Ion Lithophile Elements is also an important feature of the rocks of shoshonitic affinity. Their medium- to high-K content, and metaluminous to slightly peraluminous characters are possibly indicative of some crustal contamination during their differentiation. The conditions of $\mathrm{P}$ and $\mathrm{T}$, calculated with the geobarometer Alt-Hb and Plg-Hb thermobarometer were estimated at about 4.3 to $5.3 \mathrm{kbars}$ and crystallization temperatures on the order of 720 to $760^{\circ} \mathrm{C}$. The feldspar microstructures suggest deformation temperatures consistent with the amphibolite facies.
\end{abstract}

Keywords: Dorsal de Canguçu Shear Zone; Post-collisional Sintectonic magmatism; Shoshonitic series.

\section{INTRODUÇÃO}

Os granitoides e metagranitoides são os constituintes mais importantes da crosta terrestre, respondendo por aproximadamente $80 \%$ de seu volume total. Representam grande parte da história evolutiva da terra e são uma das mais relevantes manifestações do magmatismo orogênico em profundidade, acessível a estudos (Nardi e Bitencourt, 2007). Na região Sul do Brasil, o grande volume de rochas granitoides neoproterozoicas expostas na porção Leste do Escudo Sul-rio-grandense (ESRG), em uma faixa de direção NE que se estende de Santa Catarina ao Uruguai (Figura 1), tem sido um tema muito discutido. Para alguns autores, por exemplo, Fernandes et al. (1995), esta faixa seria o registro de uma associação de arco magmático neoproterozoico originada pela convergência entre os crátons do Kalahari e Rio de La Plata, gerando subducção de uma placa oceânica e formação de uma margem continental ativa na borda oriental do Cráton Rio de La Plata. No entanto, Bitencourt e Nardi $(1993,2000)$ relacionam este magmatismo granítico a um ambiente pós-colisional neoproterozoico e, de acordo com os mesmos, as possíveis assembleias de rochas representantes de um arco magmático na parte Leste do ESRG deveriam ser procuradas nas associações de ortognaisses que formam o embasamento deste cinturão granítico. Essa hipótese encontra suporte na recente descrição de associações tonalítico-dioríticas de idade paleoproterozoica (Gregory, Bitencourt, Nardi, 2011), que fazem parte do embasamento destes granitoides.

O presente trabalho tem como área de estudo um importante segmento representativo deste ambiente pós-colisional, no qual três granitoides sintectônicos, antes mapeados como ortognaisses e interpretados como representantes da unidade mais antiga da associação de arco magmático (Fernandes et al., 1995), foram desmembrados da mesma e relacionados ao magmatismo pós-colisional neoproterozoico. Segundo Bitencourt e Nardi (2000), a principal forma de aporte e posicionamento de magmas neste ambiente está vinculada às diversas zonas de cisalhamento transcorrente que compõem a faixa de direção NE, referida pelos mesmos como Cinturão de Cisalhamento Sul-Brasileiro (CCSB), como pode ser observado na Figura 1. A variação composicional e a evolução geoquímica do magmatismo no interior do CCSB, assim como sua estruturação, estão registradas no magmatismo granítico sintectônico encontrado no interior deste cinturão. Por meio do mapeamento geológico e da caracterização petrológica, geoquímica e estrutural desses granitoides sintranscorrentes, é possível contribuir para o melhor entendimento do significado geotectônico de estruturas de grande porte como o CCSB.

De modo geral, o magmatismo pós-colisional é representado principalmente pela formação de grandes batólitos com afinidade dominantemente cálcio-alcalina alto-K, com rochas shoshoníticas subordinadas (Liégeois, 1998; Harris, Pearce, Tindle, 1986). Granitoides de afinidade shoshonítica 




Figura 1. Compartimentação do Segmento Meridional da Província Mantiqueira, principais unidades geotectônicas do Sul do Brasil e Uruguai e localização da área de estudo (Modificado de Nardi e Bitencourt, 2007).

ocorrem tanto no interior do CCSB como associados a rochas vulcânicas, relacionadas a bacias sedimentares neoproterozoicas do tipo strilke-slip. Segundo Morrison (1980), as rochas da série shoshonítica apresentam razões $\mathrm{Na}_{2} \mathrm{O} / \mathrm{K}_{2} \mathrm{O}$ em torno de um e menor que dois, cumprindo a condição $\left(\mathrm{K}_{2} \mathrm{O}+2\right)>\mathrm{Na}_{2} \mathrm{O}$. Outras feições, em geral, utilizáveis na identificação de granitoides com esta afinidade são os teores de $\mathrm{Sr}>400 \mathrm{ppm}$ (para $\mathrm{SiO}_{2}<73$ peso \%), seu caráter metaluminoso e padrões regulares de elementos terras raras - ETR (LaN 100-300, YbN 10-5), com anomalias negativas de $\mathrm{Eu}$ apenas nos termos muito diferenciados $\left(\mathrm{SiO}_{2}>73\right.$ peso\%).

São objetivos deste trabalho: apresentar os principais aspectos estruturais e geoquímicos do Granodiorito Cruzeiro do Sul (GCS) e suas implicações na área de estudo; discriminar o ambiente tectônico e a série magmática à qual ele pertence, além de caracterizar a composição química de seus minerais máficos e determinar parâmetros de geotermobarometria, comparando os dados obtidos com outras rochas do mesmo contexto geológico.

\section{CONTEXTO GEOLÓGICO E GEOTECTÔNICO}

O Segmento Meridional da Província Mantiqueira (PM) (Almeida et al., 1977), incluindo as áreas pré-cambrianas do ESRG e sua compartimentação, conforme adotado por Nardi e Bitencourt (2007), é apresentado na Figura 1. A geologia do ESRG é composta, em grande parte, por rochas magmáticas relacionadas com o Ciclo BrasilianoPanafricano, tendo como embasamento rochas metamórficas de idade paleoproterozoica (Hartmann et al., 1999; Soliani Jr. et al., 1986).

O CCSB foi gerado durante este ciclo e compreende diversas zonas de cisalhamento anastomosadas, com espessura quilométrica e cinemática dominantemente transcorrente, sendo a maior parte destas zonas subvertical, com direção variável entre NS e N60E, e deslocamento horário ou anti-horário (Bitencourt e Nardi, 2000). Os granitoides condicionados por essa estrutura compõem uma faixa de orientação NE-SW, com cerca de $800 \mathrm{~km}$ de comprimento e largura média de $150 \mathrm{~km}$, designada Batólito Pelotas no Rio Grande do Sul, Batólito Florianópolis em Santa Catarina e Batólito Aiguá no Uruguai.

Esse cinturão granítico resulta do magmatismo de ambientes pós-colisionais, nos quais um grande volume de granitoides (630 a $580 \mathrm{Ma}$ ) está associado, em menor volume, a rochas máficas, representadas por enclaves microgranulares, diques sinplutônicos e corpos dioríticos sincrônicos.

A Zona de Cisalhamento Transcorrente Dorsal de Canguçu-ZCTDC (Fernandes, Tommasi, Porcher, 1990), 
de direção NE-SW, é a principal descontinuidade do CCSB no ESRG e tem sido motivo de diversas discussões e interpretações distintas. É interpretada por Fernandes et al. (1993) como uma zona de cisalhamento intracontinental, de escala litosférica do tipo strike-slip, apresentando uma longa história evolutiva, com diversas reativações durante o Fanerozoico (Fernandes et al., 1995), tendo uma possível continuidade física desta para a Zona de Cisalhamento Sierra Ballena, no Uruguai.

Dados reunidos por Bitencourt e Nardi (1993, 2000), Philipp, Nardi e Bitencourt (2000) e Florisbal et al. (2007) para o magmatismo no interior do CCSB permitiram estabelecer a dominância do magmatismo subalcalino médio a alto-K, na fase precoce $(650-620 \mathrm{Ma})$, seguido por associações shoshoníticas (cerca de $600 \mathrm{Ma}$ ) e associações alcalinas (590 - $580 \mathrm{Ma})$. Granitoides sintectônicos peraluminosos são descritos no intervalo de 630 a 617 Ma.

\section{GEOLOGIA DO GRANODIORITO CRUZEIRO DO SUL}

A área de estudo está localizada na região Leste do estado do Rio Grande do Sul, a cerca de $70 \mathrm{~km}$ de Porto Alegre, na região de Quitéria (Figura 1). Observa-se, nessa área, um complexo arcabouço estrutural definido por zonas de cisalhamento e de catáclase de escala regional e diversos lineamentos (Figura 2). São reconhecidas zonas de transcorrência de direção ENE e NE principais, interpretadas como parte da ZCTDC, ambas de caráter dúctil e movimento sinistral, responsáveis pela deformação e abertura

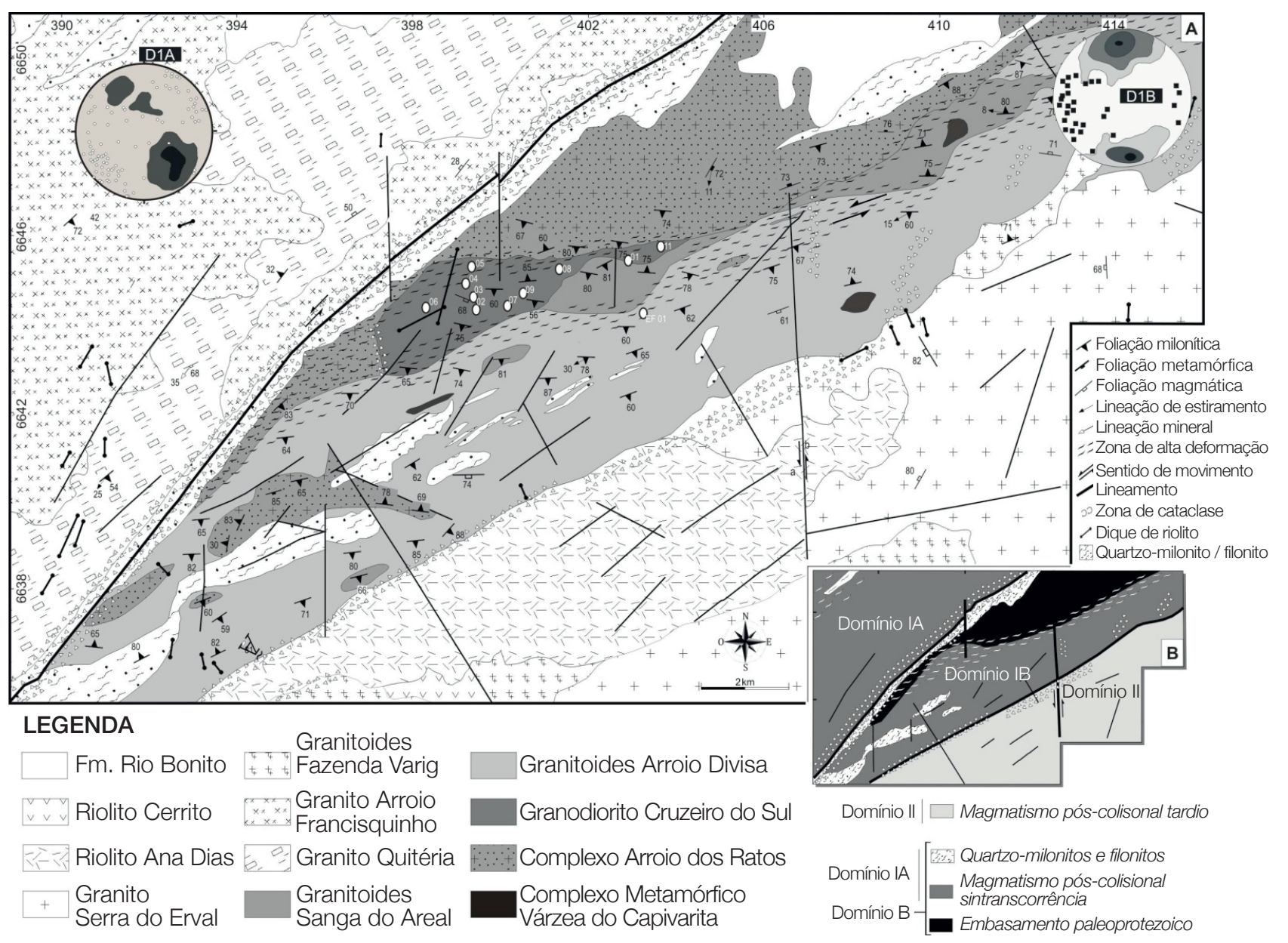

Figura 2. (A) mapa geológico da região de Quitéria-Serra do Erval; (B) mapa dos domínios estruturais e litológicos. Elipses brancas correspondem à amostragem geoquímica dos pontos DK do GCS, mais EF 01 referente a um xenólito do GCS no GAD. Projeção estereográfica em rede de Schmidt (hemisfério inferior) para os elementos estruturais dos Domínios IA (D1A) e IB (D1B) - contornos dos polos da foliação milonítica (Sm) e magmática (So); (匹 e o) lineação mineral $(L m)$ e de estiramento (Lx). D1A (Sm + So $-N=836 L x+L m-N=118)-D 1 B(S m+S o-N=533 L x+L m-N=63)-$ (modificado de UFRGS, 2006, 2007). 
de espaços sincrônicos para a colocação de diversos granitoides. Estruturas de caráter rúptil-dúctil, representadas por extensas cristas de quartzo-milonito e filonitos de direção N45E e N55E, assim como zonas de catáclase concordantes com estas estruturas também puderam ser verificadas. Ocorrem ainda diversos lineamentos N-S que cortam todas as estruturas citadas, e, em grande parte deles, identifica-se movimento sinistral, com componente oblíquo variável, que podem ser correlacionados ao Sistema Passo do Marinheiro (Picada, 1971).

A compartimentação da área em três grandes domínios está representada na Figura 2, os Domínios IA e IB são compostos pelo magmatismo pós-colisional sintranscorrente à ZCTDC, porém somente o Domínio IB está em contato com as rochas do embasamento Paleoproterozoico. A direção das estruturas também pode ser citada como diferença entre os Domínios IA e IB, enquanto o Domínio IA é francamente NE, o Domínio IB varia de ENE a EW. O limite entre os Domínios IA e IB está registrado por uma zona de catáclase N45E sobreposta às cristas de quartzo-milonitos e filonitos, que encontram-se exatamente no contato dos mesmos, portanto, essas grandes estruturas rúpteis e dúctil-rúpteis, respectivamente, impedem uma correlação de campo definitiva entre eles e justificam a individualização de dois domínios. O Domínio II, definido na porção SE da área de estudo, possui contato intrusivo com as rochas do Domínio IB e representa o magmatismo pós-colisional tardio do Batólito de Pelotas, tendo seu limite com o Domínio IB marcado pelas zonas de catáclase N55E.

O Granodiorito Cruzeiro do Sul (GCS) foi definido, pela UFRGS (2006), como uma unidade desmembrada do Complexo Gnáissico Arroio dos Ratos de Fernandes et al. (1988) por não apresentar bandamento gnáissico e constituir corpos mapeáveis na escala 1:25.000 intrusivos no Complexo, contendo xenólitos de suas litologias bandadas e, como acrescenta Knijnik (2008), por também não mostrar deformação dúctil polifásica. Segundo o mapeamento de UFRGS (2007) e Gregory (2011), que teve como área mapeada a mesma região do presente trabalho, incluindo a seção-tipo do Complexo, as litologias originalmente definidas como Complexo Gnáissico Arroio dos Ratos, na área de estudo, predominam termos sem bandamento metamórfico, retirando o termo 'Gnáissico' da nomenclatura da unidade.

As unidades mais antigas encontradas na área são septos de um embasamento Paleoproterozoico, representados por xenólitos de gnaisses cacissilicatados da Suíte Metamórfica Várzea do Capivarita e de ortognaisses, metatonalitos e metagranodiritos do Complexo Arroio dos Ratos. O GCS ocorre como um corpo, de aproximadamente $4 \mathrm{~km}^{2}$, alongado na direção ENE-WSW e controlado pela zona de cisalhamento ENE, que também abriga os granitoides mais jovens Arroio Divisa (GAD) e Sanga do Areal (GSA), também desmembrados do Complexo Arroio dos Ratos, pela UFRGS (2007), e estudados posteriormente por Fontana (2008) e Centeno (2008), como visto na Figura 2. Esses três granitoides são sintectônicos à mesma zona de cisalhamento ENE e possuem estruturas deformacionais concordantes (N65-90E) e de igual temperatura, mas suas relações de campo e, principalmente, a presença de xenólitos do GCS nos GAD e nos GSA, permitem estabelecer sua ordem estratigráfica com o GCS, como unidade mais antiga seguida pelos GAD e GSA.

Segundo diversos autores (e.g., Koester et al., 1997; Fernandes et al., 1993), os granitos Quitéria (GQ) e Arroio Francisquinho (GAF), que afloram na porção NW da área, são definidos como sintectônicos à ZCTDC, e teriam se posicionado nos estágios iniciais de movimentação da mesma. Estes granitos estão inseridos na zona de cisalhamento NE, de caráter dúctil e movimento sinistral, referida anteriormente.

A relação destes dois granitos sintectônicos (granitos Quitéria e Arroio Francisquinho) com o GCS e os granitoides Arroio Divisa e Sanga do Areal é dificultada por extensas cristas de quartzo-milonito e filonitos, com zonas de catáclase que ocorrem sobre o contato dos mesmos, não podendo assim verificar estas relações em campo. No entanto, a orientação similar dos corpos e de suas estruturas, o sentido do movimento sinistral e as intensidades de deformação são semelhantes, além de dados de geocronologia que revelam idades muito próximas: Granito Quitéria $=631 \pm 6 \mathrm{Ma}$ (Koester et al., 2001); Granito Arroio Francisquinho $=634 \pm 6 \mathrm{Ma}$ (Frantz et al., 2003) e GCS $=634 \pm 1,5 \mathrm{Ma}$ (Knijnik et al., 2010), permitindo-se correlacionar estas unidades como fazendo parte da mesma zona de cisalhamento (ZCTDC) e estágio de movimentação.

As cristas de quartzo-milonitos e filonitos de direção N45E e N55E são feições bastante expressivas na área, e sua origem ainda é motivo de controvérsia. Tendo em vista a baixa deformação verificada nestas estruturas, incompatíveis com a alta deformação sofrida pelo Granito Arroio Francisquinho, é mais provável que estas cristas tenham sido geradas em alguma fase de reativação da ZCTDC mais rasa, já em um regime dúctil-rúptil, podendo estar relacionada com as zonas de catáclase de que ocorrem sobre elas.

Apesar de a área estudada ser composta por um complexo arcabouço estrutural (Figura 2), foi possível definir uma cronologia para os eventos deformacionais e separá-los em quatro fases principais, inicialmente em condições dúcteis, evoluindo para dúcteis-rúpteis à estritamente rúpteis. A primeira fase estaria representada pela zona de cisalhamento transcorrente ENE sinistral de caráter dúctil, que abriga o GCS, os Granitoides Arroio Divisa e os Granitoides Sanga do Areal (Domínio IB, Figura 2), e pela 
zona de cisalhamento transcorrente NE sinistral de caráter dúctil que abriga os Granitos Arroio Francisquinho e Quitéria (Domínio IA). A segunda fase representaria reativações destas zonas anteriores em ambiente crustal mais raso com mesma cinemática, podendo gerar cristas de quartzo-milonitos e filonitos que limitam os Domínios IA e IB e se sobrepõem aos GAD (N45E e N55E, respectivamente), marcando a transição de um regime dúctil-ruptil para um regime rúptil responsável pela formação de uma terceira fase de movimentação, gerando diversas zonas de catáclase NE, incluindo a estrutura N55E, que limita os Domínios IB e II (Figura 2), responsável pela abertura de espaços para entrada dos granitos rasos Serra do Erval, Fazenda Varig e do riolito Ana Dias. Por fim, na quarta fase, observa-se zonas de falha NS também com movimento sinistral cortando todas as litologias da área.

\section{Estruturas do Granodiorito Cruzeiro do Sul}

O GCS possui foliação magmática marcada pelo alinhamento dimensional de feldspatos e minerais máficos, com importante componente milonítico, principalmente próximo aos contatos. Este componente milonítica é verificado pela deformação e estiramento dos cristais maiores de feldspatos, formando porfiroclastos com caudas simétricas e assimétricas (Figura 3A), além do forte alinhamento dos cristais da matriz, assim como pela recristalização e estiramento dos grãos de quartzo, que formam fitas. Basicamente, a diferença entre as duas foliações é marcada pelos grãos de feldspatos, os quais são os minerais com temperatura de deformação mais elevada presentes na rocha. Enquanto nas porções menos deformadas, principalmente no centro do corpo do GCS, os feldspatos preservam formas ígneas com faces retas e cristais subédricos a euédricos, nas porções mais deformadas os grãos de feldspatos perdem estas formas em detrimento da deformação elevada e ocorrem com formas elípticas, ovoides, tipo augen etc.

A foliação milonítica é paralela à primária, com direção EW a ENE-WSW e médio a alto ângulo de mergulho, contendo lineação de estiramento de baixo caimento para W e WSW (Figuras 3B e 4). O alto ângulo de mergulho da foliação milonítica e a baixa obliquidade da lineação de estiramento indicam cinemática transcorrente da zona de cisalhamento. O sentido de movimento esquerdo desta zona é registrado por diversos indicadores cinemáticos em escala de afloramento, como porfiroclastos de feldspatos, corpos máficos decimétricos a métricos e injeções, formando caudas assimétricas, foliações dobradas, shear bands e outras microestruturas.

Veios leucograníticos concordantes e discordantes são comuns e, em zonas de mais alta deformação, geram um bandamento composto (Figura 3C) juntamente com enclaves microgranulares máficos alongados e diques sinplutônicos de composição diorítica a tonalítica paralelos à foliação. A relação de contemporaneidade dos diques sinplutônicos com o granodiorito encaixante é dada pela ocorrência de injeções mútuas destes litotipos (Figura 3D) (UFRGS, 2006). Os enclaves máficos possuem contatos lobados e, por vezes, mostram feições de assimilação e mistura com o GCS. O granodiorito também contém xenólitos decimétricos de anfibolitos, metadioritos e gnaisses do Complexo Arroio dos Ratos (UFRGS, 2006).

Diversas estruturas são formadas sobre estas injeções leucocráticas: dobras, estruturas tipo pinch and swell (Figura 3E), boudins e formação de caudas simétricas e assimétricas (Figura 3F). Estas injeções, quando dobradas, possuem planos axiais paralelos à foliação da rocha encaixante com eixos de dobras também concordantes às lineações minerais e de estiramento do GCS. Isso demonstra um mesmo campo de tensão para a formação das dobras e da foliação milonítica do GCS, o que é também verificado na formação das estruturas tipo pinch and swell e de boudins. A progressão da deformação sobre estas injeções forma estruturas tipo pinch and swell e boudins, podendo resultar na formação de caudas simétricas e assimétricas, indicando movimento sinistral.

\section{PETROGRAFIA}

As rochas do GCS possuem duas texturas predominantes, a primeira consta de uma textura porfirítica, com foliação magmática e componente milonítica superposta, na qual os megacristais de feldspatos e alguns minerais da matriz ainda preservam formas ígneas (Figura 5A). Esta textura ocorre na maior parte do corpo e evolui em direção aos contatos Sul e Norte em zonas de alta deformação, para uma textura totalmente milonítica (definindo a segunda textura predominante), em que ocorre estiramento dos minerais e aumento da relação matriz/megacristais, porém, a composição mineralógica permanece inalterada. Os corpos máficos que ocorrem associados ao GCS são rochas de granulação fina com textura microporfirítica e foliação magmática marcada por um forte alinhamento de todos os minerais.

A textura porfirítica do GCS é definida por megacristais de feldspatos em matriz inequigranular fina a média, e a proporção de megacristais varia de 20 a $30 \%$ em relação à matriz. Os megacristais têm $1 \mathrm{a} 2 \mathrm{~cm}$ de comprimento em média, por vezes chegam a $3 \mathrm{~cm}$. Muitos cristais ainda preservam faces retas e alguns possuem formas ovoides alongadas, tipo augen. Sua orientação preferencial bem marcada e o alinhamento dos minerais da matriz definem uma foliação magmática.

Os megacristais de K-feldspatos (ortoclásio) representam $63 \%$ do total dos cristais maiores de feldspatos, 

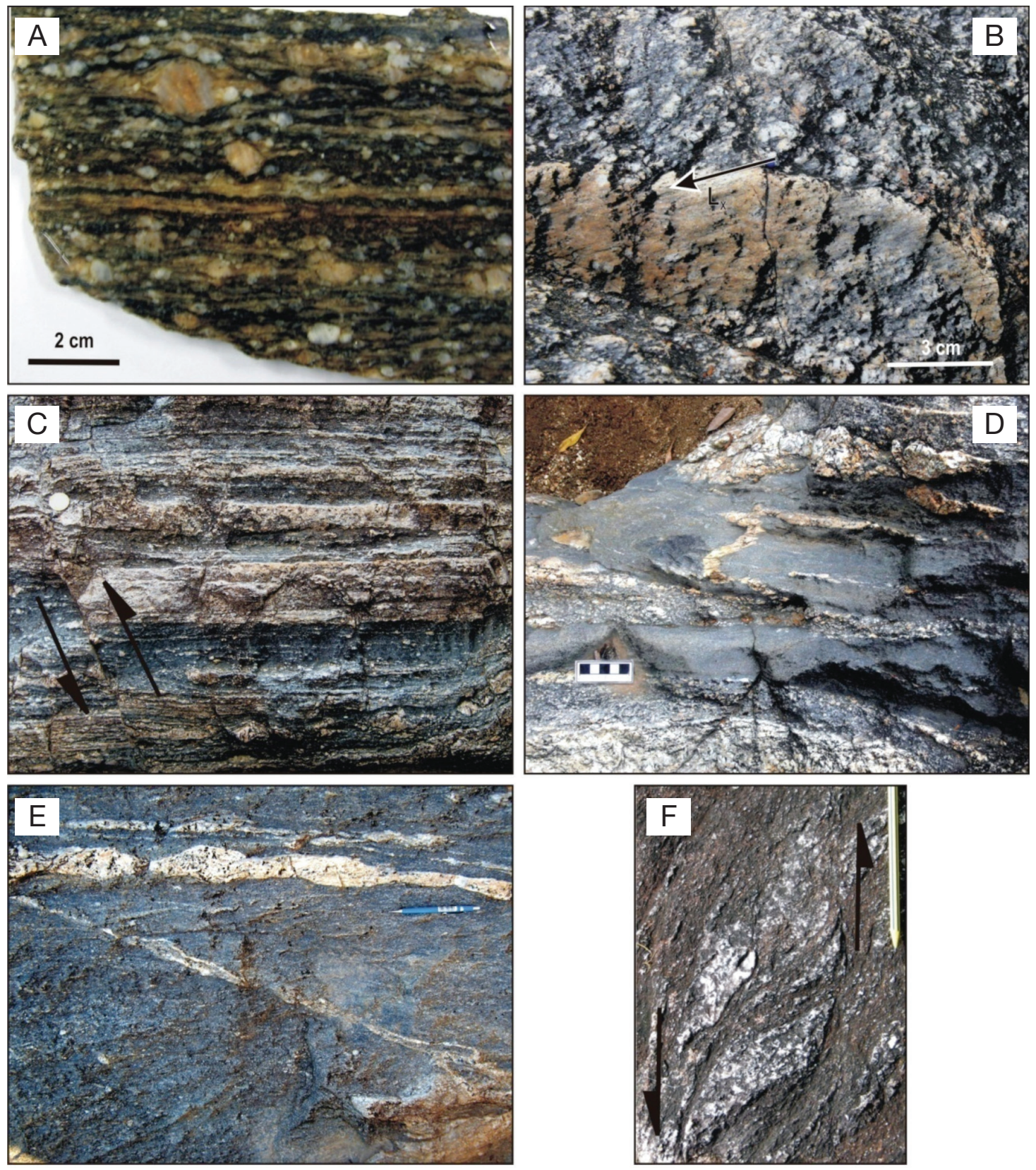

Figura 3. (A) Porfiroclastos de feldspatos com caudas simétricas e assimétricas indicando movimento sinistral; (B) detalhe da lineação de estiramento em injeção félsica que corta o GCS - Smil 097;60 e Lx 14;264 (notar o baixo ângulo de caimento da Lx), visada em corte; (C) ponto próximo ao contato do Complexo Arroio dos Ratos em zona de alta deformação; GCS com bandamento composto dado pelas injeções leucocráticas paralelas à foliação milonítica, sendo deslocado por falha rúptil dextral - Smil 094;69 e Lx 27;268; (D) dique sinplutônico máfico com relações de mutua intrusão com o GCS, cortados por injeção leucocrática dobrada; (E) injeção leucocrática com estrtura tipo pinch and swell - Smil 086;84 e (F) injeções leucocráticas com caudas assimétricas como indicador cinemático sinistral (Smil = foliação milonítica e Lx = lineação de estiramento).

predominando em relação ao plagioclásio andesina (An 31\%), em matriz granodiorítica contendo em média $20 \%$ de biotita e cerca de 5 a $10 \%$ de hornblenda. A variação da composição mineralógica do GCS não é muito pronunciada, a rocha rica em máficos $\left(M^{\prime} \sim 20\right)$ pode ser classificada como um hornblenda-biotita Granodiorito (Figura 6), com alanita e titanita como acessórios diagnósticos, além de zircão, apatita e opacos.

Os feldspatos possuem diversas microestruturas de deformação, as quais sugerem uma componente milonítica 




Figura 4. Projeção estereográfica em rede de Schmidt (hemisfério inferior) para os elementos estruturais do GCS: contornos em 1,0, 2,0 4, 0, 6,0...a 24,0\% - contorno - Sm, polos da foliação milonítica; pontos cinza - So: polos da foliação magmática; estrela - Lx: lineação de estiramento $(\mathrm{Sm}-\mathrm{N}=89$ So $-\mathrm{N}=11 \mathrm{Lx}-\mathrm{N}=30)$. superposta, tais como: a extinção ondulante presente em todos os grãos, formação de subgrãos nas bordas de alguns minerais, maclas deslocadas e textura granoblástica interlobada e serrilhada presentes pontualmente nos feldspatos da matriz (Figura 5B). Em menor quantidade, observam-se feldspatos da matriz pouco pertitizados $(<10 \%$ do grão), com pertitas do tipo filetes e vênulas. Outras texturas e estruturas que podem ser observadas localmente são aglomerados de cristais de hornblenda, que definem uma textura cumulática e faixas cataclásticas de espessura micrométrica, paralelas à foliação.

A foliação milonítica é predominante no GCS em suas porções mais deformadas, ela é definida pela orientação preferencial de porfiroclastos de feldspatos e dos minerais da matriz que encontram-se totalmente recristalizados. Em zonas de mais alta deformação, verifica-se uma diminuição do tamanho dos grãos originais da rocha pela deformação, e a proporção de porfiroclastos/matriz varia de 20:80 a 10:90, podendo ser classificada como um milonito a ultramilonito, de acordo com a classificação de Sibson (1977) para rochas de falha.

Os porfiroclastos de feldspatos possuem tamanho entre 2 e $6 \mathrm{~mm}$, chegando até $1 \mathrm{~cm}$. A distinção dos K-feldspatos e dos plagioclásios é bastante difícil, devido à alteração
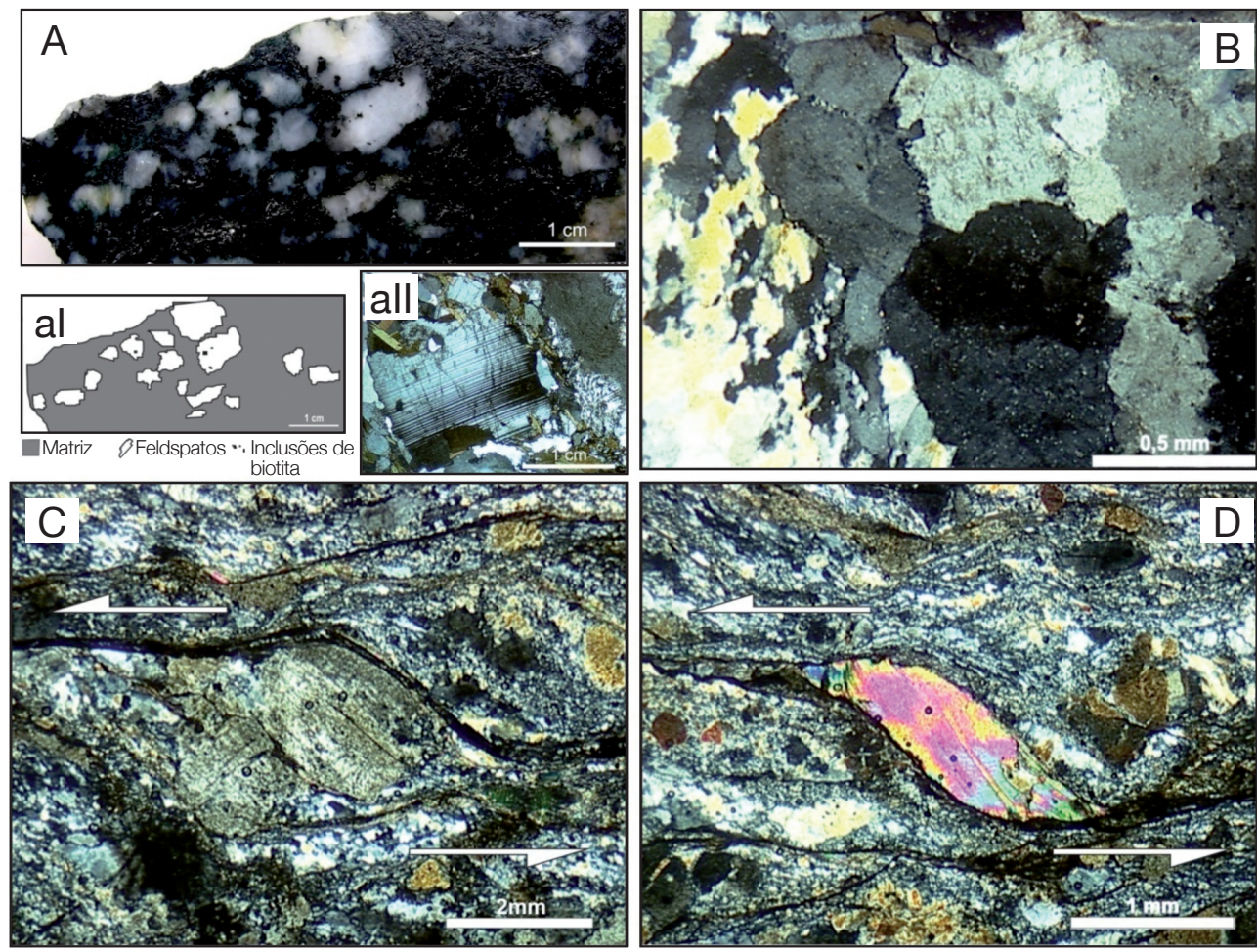

Figura 5. (A) Amostra DK01E com foliação ígnea definida pelo alinhamento dimensional dos grãos de feldspatos que preservaram algumas faces retas; al: croqui da amostra; all: fotomicrografia de um plagioclásio da matriz com as mesmas características de grãos ígneos sem deformação; (B) textura granoblástica nos feldspatos da matriz; (C) porfiroclasto com cauda de recristalização assimétricas indicando direção de movimento lateral esquerdo; (D) indicador cinemático esquerdo, do tipo mica fish. 


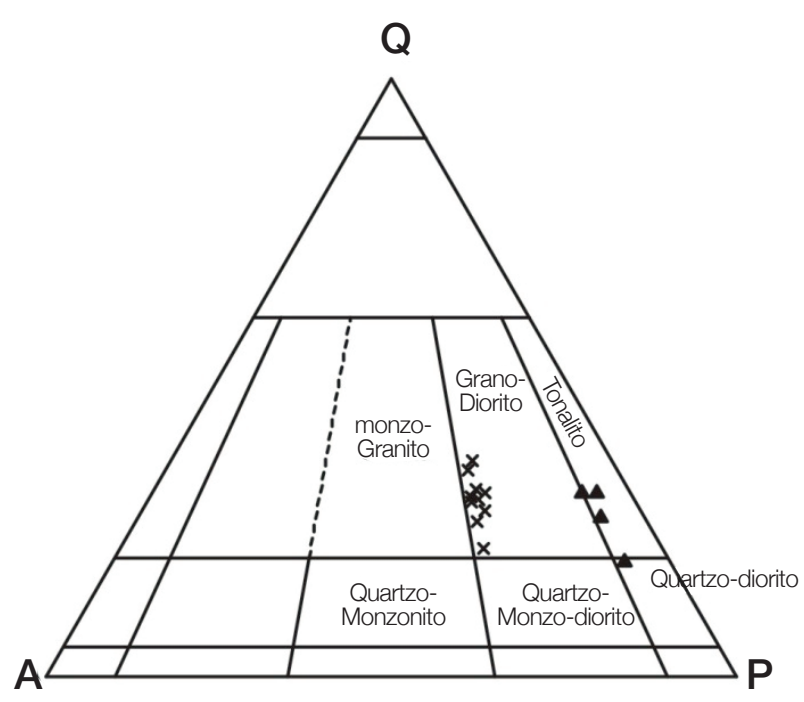

Figura 6. Amostras do GCS $(X)$ e corpos máficos associados ( $\mathbf{\Delta})$, no diagrama QAP (Streckeisen, 1976).

total ou parcial para mica branca (sericitização) dos mesmos. Ocorrem formando augens, porfiroclastos com caudas de recristalização assimétricas, indicando direção de movimento sinistral (Figura 5C) e microestruturas do tipo book shelf também são observadas como indicadores sinistrais. A extinção ondulante é vista em todos os grãos. Subgrãos nas bordas dos cristais também são bastante comuns.

A matriz quartzo-feldspática é fina a muito fina. Os grãos de quartzo da matriz possuem extinção ondulante, e ocorrem como agregados microgranulares com textura granoblástica de contatos interlobados, formando fitas e, por vezes, em forma de $S$, indicando sentido de movimento sinistral. Estruturas de estrangulamento tipo pinch and swell sobre estas fitas de quartzo e subgrãos de quartzo também são observadas.

No GCS milonítico ocorre intensa venulação, quase sempre concordante com a foliação, composta por quartzo, epidoto, opacos e muscovita, sendo que este mineral ilustra belíssimos indicadores de movimento sinistral, do tipo mica fish (Figura 5D). Acredita-se que estas venulações sejam um hidrotermalismo relacionado com a zona de cisalhamento na qual o GCS está inserido, podendo estarem relacionadas com a sericitização dos feldspatos.

Com base nas microestruturas desenvolvidas sobre os feldspatos, como subgrãos e recristalização granoblástica pontual, pode-se atribuir temperaturas na ordem de $550^{\circ} \mathrm{C}$ para deformação desta litologia, enquanto as microestruturas dos grãos de quartzo balizam as temperaturas mais baixas (em torno de $250^{\circ} \mathrm{C}$ ) do que a zona de cisalhamento atingiu.

Os corpos máficos analisados são representados por diques sinplutônicos, seu contato com o GCS é difuso, marcado por um acúmulo de biotitas orientadas segundo a foliação da encaixante, ocorre mútua intrusão e alguns cristais das duas litologias são englobados entre as mesmas. Possuem textura microporfirítica definida por cristais milimétricos de feldspatos em matriz equigranular muito fina.

A matriz é composta por quartzo, biotita, plagioclásio e raros cristais de K-feldspato, podendo ocorrer também hornblenda. Como acessório, observa-se apatita e alanita. A variação da composição mineralógica destes corpos é verificada nos teores de feldspato potássico, plagioclásio e quartzo. Enquanto o teor de máficos fica em torno de $20 \%$, representado basicamente pela biotita e em menor proporção pelo anfibólio, permitindo classificar estas litologias como hornblenda - biotita tonalitos a hornblenda - biotita - quartzo dioritos (Figura 6).

Os cristais de feldspatos, que definem a textura microporfirítica, são plagioclásios com teor de An entre 36 e 39\% equivalente ao plagioclásio andesina e, em menor proporção, K-feldspatos (ortoclásio). A maior parte deles encontra-se sericitizado e preserva faces retas. Denotando assim que estes corpos não sofreram o mesmo grau de deformação imposta sobre o GCS. Poucos grãos de feldspatos com inclusões de biotita podem ser observados, a maioria dos microfenocristais é límpido; e menos comum é a textura mirmequítica.

Diversas são as microestruturas presentes nos feldspatos, a extinção ondulante é a mais comum, maclas polissintéticas deslocadas também podem ser encontradas. Pontualmente, observam-se feldspatos com textura granoblástica interlobada e fraturamento segundo o plano de clivagem 001 (perpendicular à macla). O quartzo possui extinção ondulante, está, no geral, recristalizado, e alguns formam subgrãos. Com base nas microestruturas encontradas, sugerem-se temperaturas de deformação de no máximo $500^{\circ} \mathrm{C}$ para esta litologia.

\section{GEOQUÍMICA}

Determinações de elementos maiores e traços, incluindo elementos terras raras, foram realizadas em dez amostras representativas do GCS e quatro de rochas máficas associadas (Tabelas 1 a 3). Visando obter uma distribuição espacial representativa e procurando abranger os diferentes tipos texturais e composicionais selecionados previamente, com base em critérios de campo e petrográficos, as análises tiveram objetivo de classificar as rochas em relação às séries magmáticas e ao ambiente geotectônico e investigar sua gênese. Para a realização deste estudo, as amostras foram preparadas no Anexo do Laboratório de Geologia Isotópica do IG/UFRGS e enviadas para análise por ICP-MS para elementos traço e ICP-AES para elementos maiores no Activation Laboratories, Canadá. O limite 
Tabela 1. Resultados analíticos para elementos maiores do Granodiorito Cruzeiro do Sul e rochas máficas associadas.

\begin{tabular}{lccccccccccccc}
\hline Amostra & Rocha & $\mathrm{SiO}_{2}$ & $\mathrm{Al}_{2} \mathrm{O}_{3}$ & $\mathrm{Fe}_{2} \mathrm{O}_{3}(\mathrm{~T})$ & $\mathrm{MnO}$ & $\mathrm{MgO}$ & $\mathrm{CaO}$ & $\mathrm{Na}_{2} \mathrm{O}$ & $\mathrm{K}_{2} \mathrm{O}$ & $\mathrm{TiO}_{2}$ & $\mathrm{P}_{2} \mathrm{O}_{5}$ & $\mathrm{PF}$ & Total \\
\hline DK-01 B & $\mathrm{CP}$ & 72,09 & 14,89 & 1,08 & 0,017 & 0,34 & 1,54 & 2,85 & 5,7 & 0,255 & 0,1 & 0,63 & 99,49 \\
DK-01 E & $\mathrm{CP}$ & 66,03 & 15,05 & 5,88 & 0,129 & 2,19 & 3,27 & 2,64 & 3,38 & 0,784 & 0,22 & 1,39 & 101 \\
DK-02 A & $\mathrm{CP}$ & 66,62 & 15,36 & 5,1 & 0,073 & 1,89 & 3,71 & 2,74 & 2,54 & 0,781 & 0,31 & 1,22 & 100,3 \\
DK-03 C & $\mathrm{CP}$ & 67,24 & 13,72 & 6,12 & 0,108 & 1,9 & 2,39 & 2,58 & 2,96 & 0,981 & 0,06 & 1,6 & 99,65 \\
DK-03 D & $\mathrm{CP}$ & 55,14 & 15,99 & 7,91 & 0,185 & 4,02 & 5,47 & 2,22 & 3,02 & 1.665 & 0,86 & 2,19 & 98,66 \\
DK-04 B & $\mathrm{CP}$ & 70,27 & 14,13 & 2,2 & 0,031 & 0,65 & 2,07 & 3,02 & 4,62 & 0,298 & 0,11 & 1,04 & 98,43 \\
DK-06 A & $\mathrm{CP}$ & 67,08 & 14,53 & 4,03 & 0,062 & 1,28 & 3,25 & 3,03 & 3,67 & 0,63 & 0,2 & 0,91 & 98,67 \\
DK-08 B & $\mathrm{CP}$ & 65,06 & 14,67 & 5,07 & 0,079 & 2,2 & 3,39 & 2,66 & 3,41 & 0,888 & 0,29 & 1,49 & 99,22 \\
DK-09 B & $\mathrm{CP}$ & 60,44 & 16,65 & 5,74 & 0,1 & 2,03 & 4,11 & 3,73 & 4,01 & 1.034 & 0,39 & 1,74 & 99,97 \\
DK-10 A & $\mathrm{CP}$ & 64,89 & 17,39 & 3,76 & 0,051 & 1,16 & 4,14 & 3,49 & 3,21 & 0,622 & 0,2 & 1,14 & 100,1 \\
DK-10 B & CP & 65,17 & 17,01 & 3,57 & 0,052 & 1,08 & 3,85 & 3,36 & 3,6 & 0,574 & 0,19 & 0,98 & 99,44 \\
EF-01 A & XCP & 65,63 & 14,86 & 4,12 & 0,104 & 1,53 & 2,78 & 3,35 & 3,03 & 0,657 & 0,46 & 2,42 & 98,98 \\
DK-01 G & RMA & 68,5 & 15,53 & 3,05 & 0,035 & 1,13 & 3,63 & 3,72 & 1,52 & 0,679 & 0,17 & 1,23 & 99,22 \\
DK-03 B & RMA & 54,44 & 16,62 & 7,32 & 0,155 & 4,07 & 6,95 & 1,77 & 2,14 & 1.107 & 0,44 & 4,43 & 99,46 \\
DK-04 A & RMA & 66,13 & 15,95 & 3,47 & 0,042 & 1,55 & 3,24 & 3,73 & 3,21 & 0,738 & 0,19 & 1,39 & 99,65 \\
DK-08 D & RMA & 67,98 & 15,33 & 2,71 & 0,031 & 1,11 & 3,42 & 4 & 1,68 & 0,608 & 0,15 & 1,88 & 98,9 \\
\hline
\end{tabular}

Óxidos em peso\%, PF: perda ao fogo $\left(900^{\circ} \mathrm{C}\right)$; CP: corpo principal do GCS; RMA: rochas máficas associadas; XCP: xenólito do corpo principal.

Tabela 2. Resultados analíticos para elementos traço das amostras representativas do Granodiorito Cruzeiro do Sul e rochas máficas associadas.

\begin{tabular}{lcccccccccccccccc}
\hline Amostra & Rocha & $\mathrm{Y}$ & $\mathrm{Zr}$ & $\mathrm{V}$ & $\mathrm{Ba}$ & $\mathrm{Sr}$ & $\mathrm{Co}$ & $\mathrm{Ni}$ & $\mathrm{Ga}$ & $\mathrm{Rb}$ & $\mathrm{Nb}$ & $\mathrm{Hf}$ & $\mathrm{Ta}$ & $\mathrm{Th}$ & $\mathrm{U}$ & $\mathrm{Cs}$ \\
\hline DK-01 B & $\mathrm{CP}$ & 6 & 106 & 12 & 607 & 261 & 2 & $<20$ & 22 & 199 & 11 & 3,3 & 1,4 & 10,2 & 3,9 & 5,1 \\
DK-01 E & $\mathrm{CP}$ & 27 & 245 & 91 & 727 & 300 & 14 & 30 & 21 & 164 & 15 & 7,1 & 1,3 & 5,2 & 1,7 & 7,3 \\
DK-02 A & $\mathrm{CP}$ & 21 & 226 & 79 & 1208 & 507 & 11 & $<20$ & 22 & 151 & 11 & 6,6 & 0,8 & 14,5 & 1,6 & 13,9 \\
DK-03 C & $\mathrm{CP}$ & 9 & 388 & 112 & 944 & 414 & 15 & 30 & 21 & 172 & 14 & 11,2 & 1,1 & 13,7 & 2,8 & 19,8 \\
DK-03 D & $\mathrm{CP}$ & 19 & 286 & 137 & 1493 & 879 & 21 & 60 & 24 & 187 & 15 & 6,3 & 1 & 4,6 & 2,4 & 13,8 \\
DK-04 B & $\mathrm{CP}$ & 4 & 164 & 32 & 1495 & 471 & 5 & 20 & 17 & 110 & 3 & 5 & 0,2 & 5,6 & 0,5 & 2,3 \\
DK-06 A & $\mathrm{CP}$ & 10 & 203 & 67 & 1103 & 477 & 13 & 40 & 18 & 112 & 9 & 5,4 & 0,5 & 5,4 & 1,2 & 5,2 \\
DK-08 B & $\mathrm{CP}$ & 22 & 259 & 99 & 1112 & 509 & 13 & 20 & 21 & 176 & 16 & 7,1 & 1,5 & 16,6 & 3,8 & 14,7 \\
DK-09 B & $\mathrm{CP}$ & 25 & 359 & 86 & 1485 & 583 & 13 & $<20$ & 23 & 146 & 21 & 9,1 & 1 & 10,3 & 1,1 & 6,1 \\
DK-10 A & $\mathrm{CP}$ & 14 & 123 & 58 & 1137 & 388 & 8 & $<20$ & 24 & 139 & 10 & 3,4 & 0,7 & 9 & 1,5 & 9,1 \\
DK-10 B & $\mathrm{CP}$ & 12 & 240 & 54 & 1101 & 350 & 7 & $<20$ & 23 & 144 & 11 & 6,5 & 1 & 3 & 2,1 & 8,7 \\
EF-01 A & XCP & 28 & 306 & 57 & 1516 & 680 & 12 & $<20$ & 27 & 228 & 20 & 8 & 3 & 22 & 5,4 & 21,4 \\
DK-01 G & RMA & 5 & 206 & 45 & 726 & 568 & 7 & $<20$ & 20 & 83 & 8 & 5,7 & 0,5 & 8,3 & 1,7 & 3,5 \\
DK-03 B & RMA & 26 & 231 & 158 & 960 & 735 & 18 & $<20$ & 22 & 156 & 18 & 6,3 & 1,3 & 15,2 & 2,9 & 18,6 \\
DK-04 A & RMA & 10 & 220 & 78 & 799 & 454 & 7 & $<20$ & 27 & 128 & 8 & 6 & 0,5 & 12,1 & 1,4 & 6,8 \\
DK-08 D & RMA & 5 & 182 & 43 & 559 & 583 & 5 & $<20$ & 18 & 79 & 8 & 4,9 & 0,4 & 7,8 & 1,3 & 4,4 \\
\hline
\end{tabular}

Elementos traço em PPM. CP: corpo principal do GCS; RMA: rochas máficas associadas; XCP: xenólito do corpo principal. 
Tabela 3. Resultados Analíticos para os elementos terras raras das amostras representativas do Granodiorito Cruzeiro do Sul e rochas máficas associadas.

\begin{tabular}{lccccccccccccccc}
\hline Amostra & Rocha & La & Ce & Pr & Nd & Sm & Eu & Gd & Tb & Dy & Ho & Er & Tm & Yb & Lu \\
\hline DK-01 B & CP & 24 & 45,6 & 5,31 & 17,1 & 3,1 & 0,87 & 2 & 0,3 & 1,4 & 0,2 & 0,6 & 0,08 & 0,4 & 0,06 \\
DK-01 E & CP & 24,2 & 48,3 & 6,14 & 21,6 & 4,7 & 1,21 & 4,3 & 0,8 & 5,1 & 1 & 2,7 & 0,4 & 2,5 & 0,36 \\
DK-02 A & CP & 52,8 & 105 & 12,8 & 40 & 7,5 & 1,59 & 5,4 & 0,8 & 4,4 & 0,8 & 2,1 & 0,3 & 1,8 & 0,26 \\
DK-03 C & CP & 53,6 & 100 & 11,2 & 29,9 & 4,9 & 1,08 & 2,9 & 0,4 & 2 & 0,3 & 0,9 & 0,12 & 0,8 & 0,13 \\
DK-03 D & CP & 49 & 107 & 14,1 & 47,2 & 9,3 & 2,21 & 6,6 & 1 & 4,6 & 0,7 & 1,8 & 0,24 & 1,4 & 0,18 \\
DK-04 B & CP & 38,4 & 50,7 & 5,3 & 14,2 & 2,2 & 0,94 & 1,5 & 0,2 & 0,9 & 0,2 & 0,4 & 0,06 & 0,4 & 0,07 \\
DK-06 A & CP & 69,1 & 67 & 7,2 & 20,4 & 3,5 & 1,12 & 2,6 & 0,4 & 2,2 & 0,4 & 1 & 0,14 & 0,9 & 0,13 \\
DK-08 B & CP & 26 & 134 & 15,4 & 45,3 & 8 & 1,69 & 5,7 & 0,9 & 4,8 & 0,9 & 2,3 & 0,33 & 2,2 & 0,33 \\
DK-09 B & CP & 40,7 & 123 & 14,4 & 46 & 8,6 & 2,07 & 6,8 & 1,1 & 5,9 & 1 & 2,6 & 0,36 & 2,2 & 0,3 \\
DK-10 A & CP & 17,2 & 77,5 & 8,67 & 25,2 & 4,7 & 1,9 & 3,7 & 0,6 & 3 & 0,5 & 1,4 & 0,19 & 1,2 & 0,15 \\
DK-10 B & CP & 85,6 & 33 & 3,98 & 13,5 & 2,9 & 1,61 & 2,8 & 0,5 & 2,7 & 0,5 & 1,4 & 0,2 & 1,2 & 0,17 \\
EF-01 A & XCP & 85,6 & 171 & 21 & 65 & 12,5 & 2,14 & 8,7 & 1,2 & 6,1 & 1,1 & 2,8 & 0,4 & 2,3 & 0,3 \\
DK-01 G & RMA & 24,6 & 49,7 & 6,14 & 19,9 & 3,6 & 1,02 & 2,5 & 0,3 & 1,4 & 0,2 & 0,6 & 0,08 & 0,5 & 0,06 \\
DK-03 B & RMA & 68,5 & 132 & 15,8 & 48,9 & 9,1 & 2,52 & 6,6 & 1 & 5,4 & 1 & 2,5 & 0,35 & 2,2 & 0,29 \\
DK-04 A & RMA & 38,2 & 75,2 & 9,01 & 27,8 & 5,2 & 1,18 & 3,3 & 0,5 & 2,3 & 0,4 & 1 & 0,14 & 0,9 & 0,13 \\
DK-08 D & RMA & 60,9 & 50,7 & 6,06 & 18,8 & 3,6 & 1 & 2,5 & 0,3 & 1,5 & 0,2 & 0,5 & 0,07 & 0,4 & 0,05 \\
\hline
\end{tabular}

ETR em ppm. CP: corpo principal do GCS; RMA: rochas máficas associadas; XCP: xenólito do corpo principal.

de detecção para maioria dos elementos maiores foi na ordem de $0,01 \%$ e de sub-ppb para os elementos traço.

Os resultados das análises químicas das amostras foram plotados em diagramas binários, tendo $\mathrm{SiO}_{2}$ como índice de diferenciação (Figura 7). $\mathrm{O}$ conteúdo de $\mathrm{SiO}_{2}$ no granodiorito e nas rochas máficas varia de $54 \mathrm{a} 72 \%$, com valores relativamente altos de $\mathrm{Al}_{2} \mathrm{O}_{3}$ de 14 a $17 \%$, em peso. $\mathrm{O} \mathrm{Na}_{2} \mathrm{O}$ e o $\mathrm{K}_{2} \mathrm{O}$ apresentam comportamento irregular nos diagramas, enquanto que os demais óxidos mostram correlações negativas com o aumento de $\mathrm{SiO}_{2}$. Os decréscimos de $\mathrm{TiO}_{2}, \mathrm{MgO}, \mathrm{AlO}_{3}, \mathrm{Fe}_{2} \mathrm{O}_{3}(\mathrm{~T}), \mathrm{CaO}$ e $\mathrm{P}_{2} \mathrm{O}_{5}$, com a evolução da diferenciação, podem ser atribuídos ao fracionamento de fases minerais, tais como: hornblenda, biotita, plagioclásio, titanita, e apatita.

Os trends lineares e retilíneos apresentados por óxidos de elementos compatíveis, como $\mathrm{CaO}, \mathrm{MgO}, \mathrm{TiO}_{2}$, $\mathrm{Fe}_{2} \mathrm{O}_{3}(\mathrm{~T})$, sugerem que a contaminação dos magmas por fusões félsicas podem ter contribuído no processo de diferenciação.

Por meio do gráfico álcalis $\left(\mathrm{Na}_{2} \mathrm{O}+\mathrm{K}_{2} \mathrm{O}\right)$ em função da sílica $\left(\mathrm{SiO}_{2}\right)$ (Figura 8), pode-se identificar as rochas estudadas como pertencentes à série subalcalina, supersaturada em sílica, com teor de álcalis $\left(\mathrm{Na}_{2} \mathrm{O}+\mathrm{K}_{2} \mathrm{O}\right)$ variando de 4,3 a $7,74 \%$ em peso, e razão $\mathrm{Na}_{2} \mathrm{O} / \mathrm{K}_{2} \mathrm{O} \sim$ 1 , valor correspondente à série shoshonítica, de acordo com Morrison (1980). As variações dos teores de potássio $\left(\mathrm{K}_{2} \mathrm{O}\right)$, em função da sílica $\left(\mathrm{SiO}_{2}\right)$, identificam teores médios a altos de $\mathrm{K}_{2} \mathrm{O}$ para as amostras do GCS, sendo os valores mais baixos encontrados nos corpos máficos (Figura 9). O caráter predominantemente peraluminoso pode ser observado no diagrama de Shand (1943), na Figura 10. A afinidade não toleítica destas rochas é indicada pelo diagrama $\left(\mathrm{Fe}_{\text {tot }}+\mathrm{Ti}\right)-\mathrm{Al}-\mathrm{Mg}$, de Jensen (1976), como pode ser observado na Figura 11. No diagrama R1R2 de De La Roche et al. (1980), as amostras do GCS correspondem composicionalmente a granodioritos, com uma leve tendência a composições tonalíticas e dioríticas (Figura 12).

Os altos teores de $\mathrm{Sr}$ (entre 300 e 900 ppm, em média $530 \mathrm{ppm}$ ) sugerem a afinidade shoshonítica do magmatismo, e valores semelhantes de Ba e Sr para os componentes máficos e félsicos sugerem que os magmas são cogenéticos. Padrões de elementos traços com enriquecimento em $\mathrm{Ba}$ e $\mathrm{Rb}$ e empobrecimento de high field strengthHFS (Th, Ta, Nb, Ce, Hf, Zr, e Y), em relação aos Large Ion Lithophile Elements - LILE (K, Rb, e Ba) (Figura 13), também são características importantes das rochas de afinidade shoshonítica. Comparando as amostras do GCS no diagrama multielemetar (Figura 13) com amostras da Associação Shoshonítica Lavras do Sul, de Lima e Nardi (1998), é possível observar um padrão muito similar entre as duas.

As concentrações de ETR (expressas em valores que foram normalizados pelos conteúdos condríticos) (Figura 14), definem padrões com moderado a forte fracionamento dos ETR pesadas (ETRP) em relação aos ETR leves 

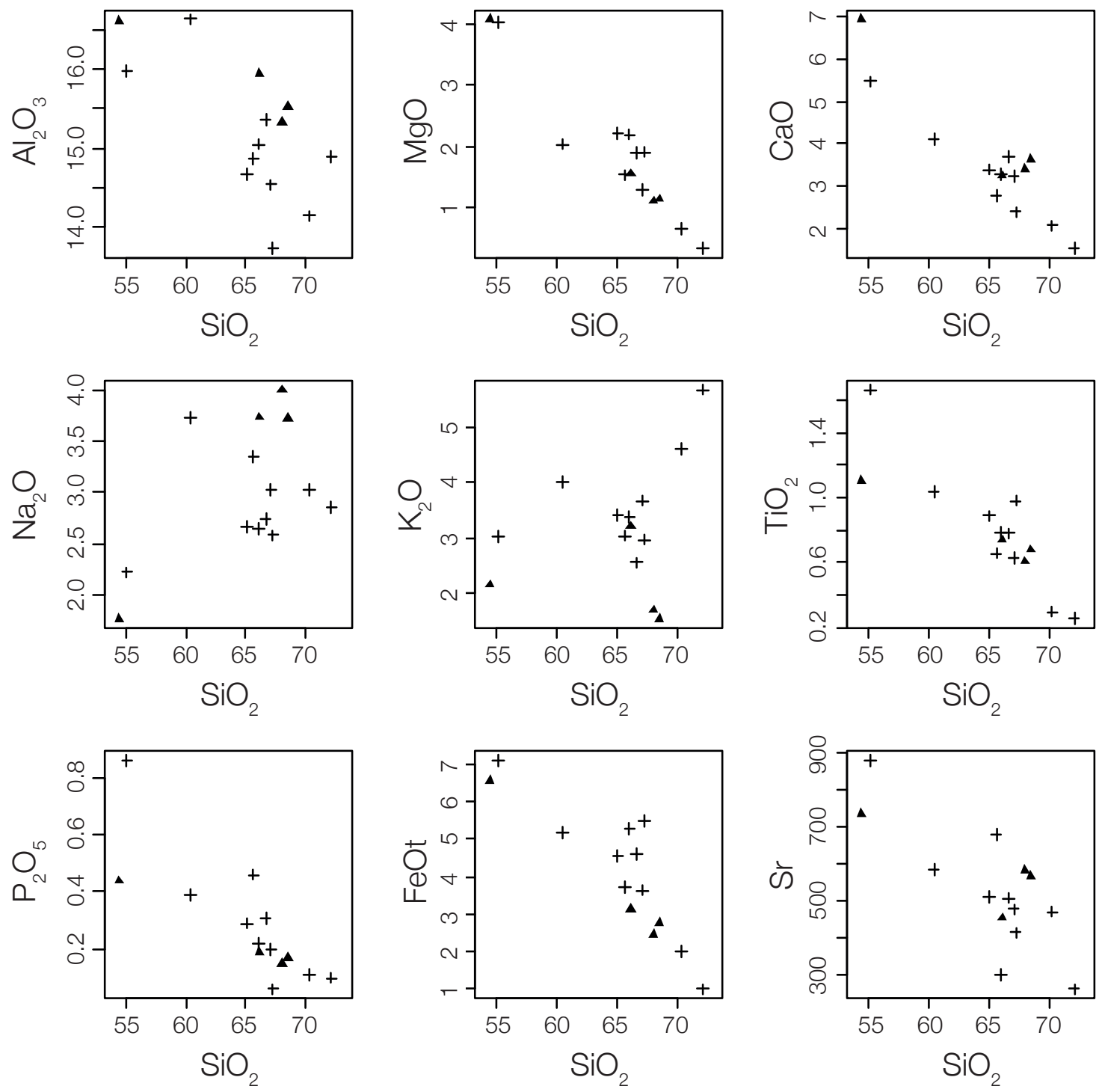

Figura 7. Diagramas de Harker dos elementos maiores e traço (Sr) tendo sílica como índice de diferenciação. GCS (+) e diques máficos sinplutônicos associados $(\mathbf{\Delta})$.

(ETRL), com razões de CeN/YbN variando de 14 a 29 e em média 21. O conteúdo de ETRL $(\mathrm{CeN} \sim 111)$ relativamente elevado, YbN entre 1,91 e 11 (em média 6,46) e ausência de anomalias significativas de Eu são feições típicas do magmatismo shoshonítico. As razões de Eu/Eu* (concentração de európio/ európio esperado) são dadas pela equação $\mathrm{EuN} /[(\mathrm{SmN}+\mathrm{GdN}) / 2]$, com valores em torno de 0,95 e variando entre 0,63 e 1,14 demonstrando pequenas anomalias positivas e negativas de Eu. O fracionamento dos ETRP é dado pela razão $(\mathrm{Eu} / \mathrm{Yb}) \mathrm{N} 4$ e dos ETRL $(\mathrm{La} / \mathrm{Sm}) \mathrm{N} \sim 5$. O comportamento linear e homogêneo dos elementos terras raras, mesmo para rochas com diferentes graus de diferenciação, aponta para a afinidade shoshonítica do magmatismo.
Os diagramas discriminantes de ambientes geotectônicos indicam ambiente de margem continental ativa evoluindo para magmatismo intraplaca (Figura 15). Seus padrões de elementos traços são similares aos de granitoides pós-colisionais, com enriquecimento em $\mathrm{Rb}$.

\section{Química mineral das fases máficas}

\section{Anfibólio e biotita}

\section{Variação composicional e geotermobarometria}

Anfibólios e biotitas foram analisados no Centre for Microscopy and Microanalysis da University of Western 


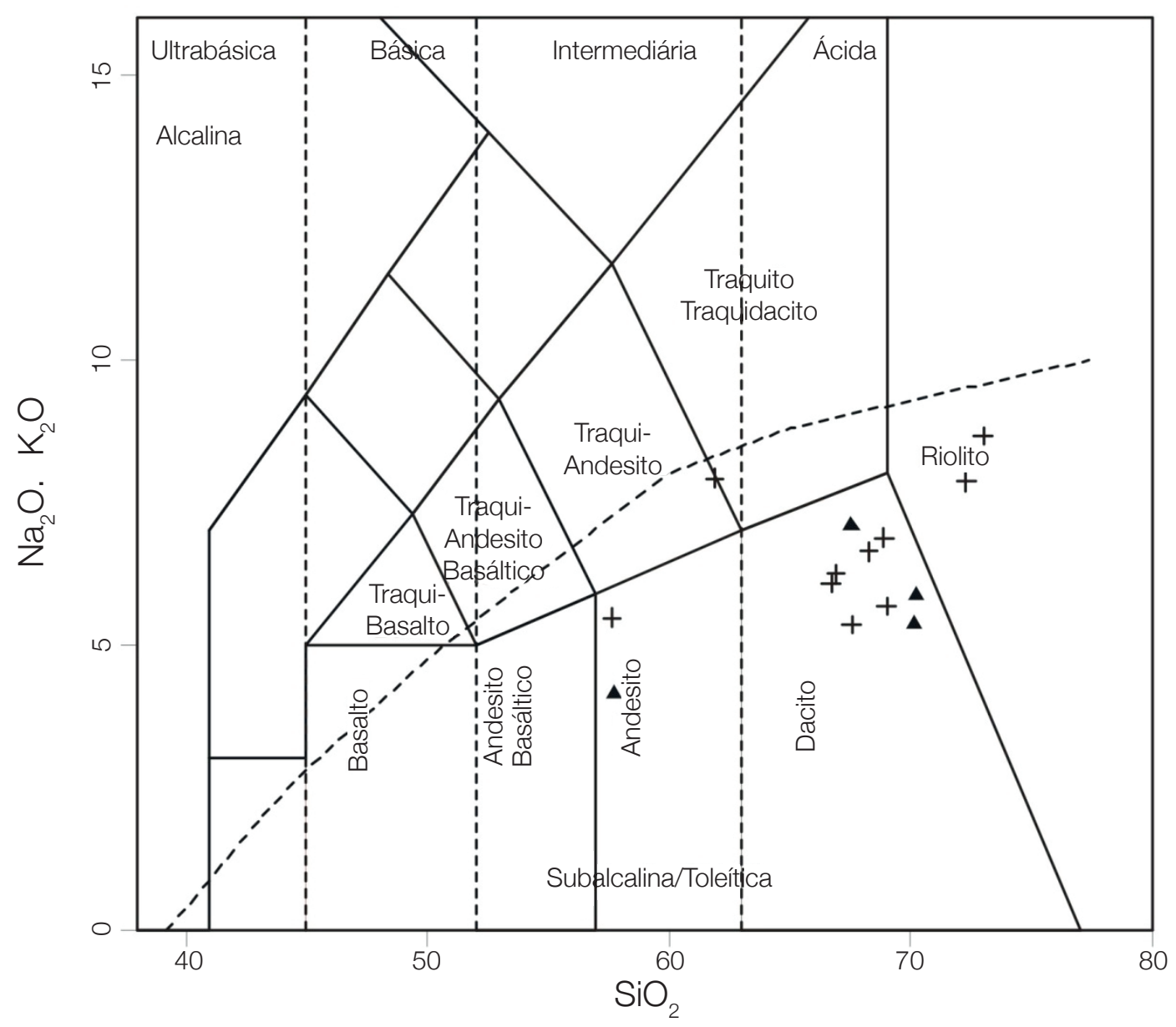

Figura 8. Diagrama TAS de Le Bas et al. (1986), com as amostras do GCS (+) e diques máficos sinplutônicos associados (ム) plotando no campo da série subalcalina, supersaturada em sílica.

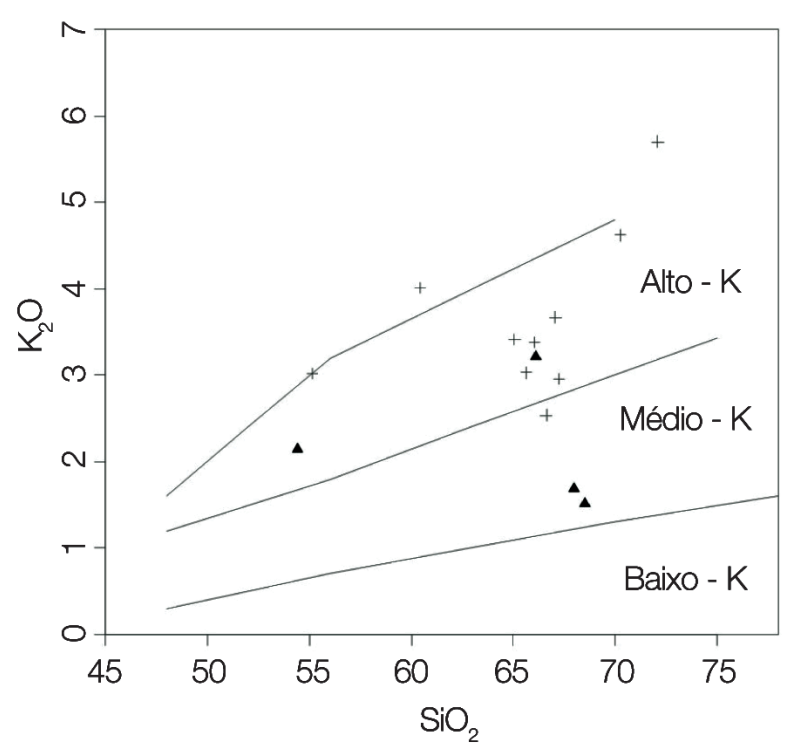

Figura 9. Diagrama discriminante $\mathrm{K}_{2} \mathrm{O}-\mathrm{SiO}_{2}$ de Le Maitre (2002), com as amostras do GCS (+) e diques máficos sinplutônicos associados $(\mathbf{\Lambda})$.

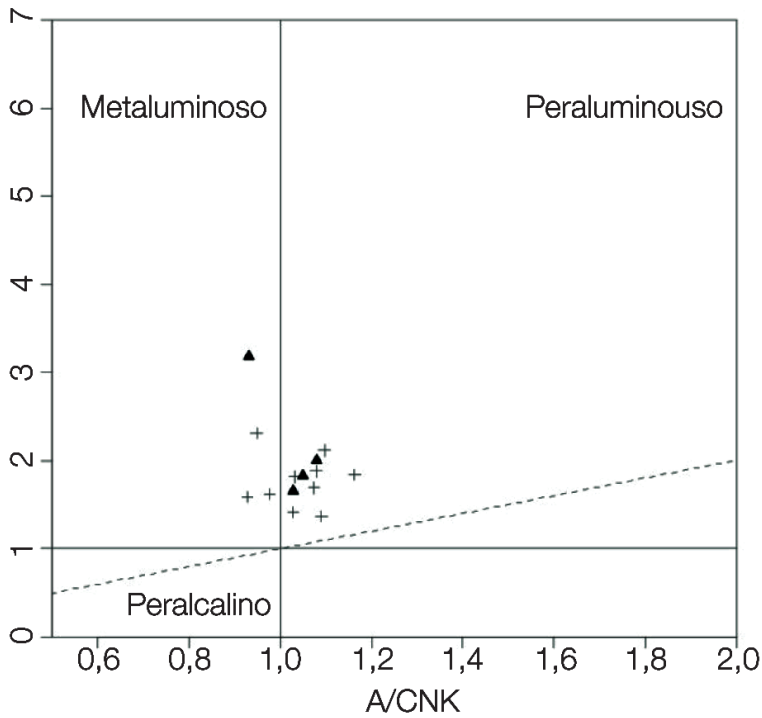

Figura 10. Diagrama discriminante $A / C N K \times A / N K$ de Shand (1943), com as amostras do GCS (+) e diques máficos sinplutônicos associados $(\mathbf{\Lambda})$, evidenciando o caráter levemente peraluminoso das rochas analisadas. 


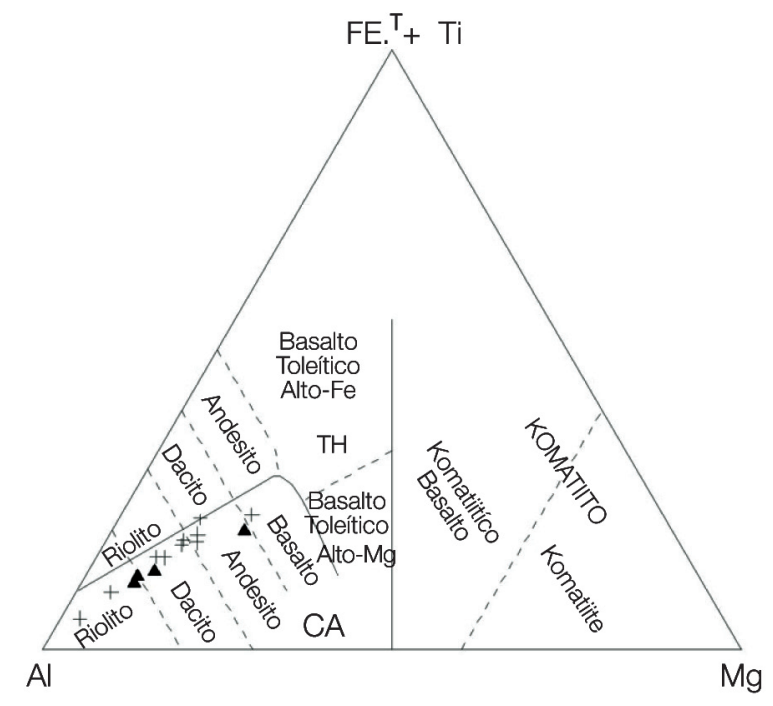

Figura 11. Diagrama ternário $\mathrm{Fe}+\mathrm{Ti} \times \mathrm{Mg} \times \mathrm{Al}$ de Jensen (1976), com as amostras do GCS (+) e diques máficos sinplutônicos associados $(\boldsymbol{\Delta})$, demonstrando afinidade não toleítica.

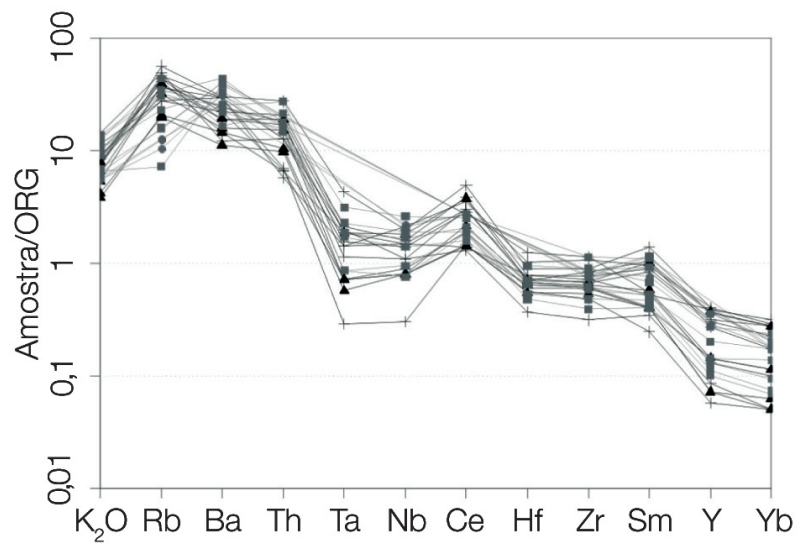

Figura 13. Diagrama multielementar, com normalização pelos valores de granitos de cadeias mesooceânicas (ORG) de Pearce et al. (1984). GCS (+); diques máficos sinplutônicos associados ( $\mathbf{\Delta}$ ) e ASLS (ロ) de Lima e Nardi (1998).

Australia (UWA), utilizando o aparelho JEOL JSM-6400. As fórmulas estruturais dos anfibólios foram calculadas na base de 23 átomos de oxigênio, utilizando-se o esquema de normalização 13 e CNK ( $\mathrm{S}$ de cátions = 13, excluindo-se $\mathrm{Ca}, \mathrm{Na}$ e K). As fórmulas estruturais das biotitas foram calculadas a 24 átomos de oxigênio, assumindo-se todo o ferro presente como $\mathrm{Fe}^{2+}$. O software MINPET, versão 2.02 (Richard, 1995), foi utilizado para obtenção das fórmulas estruturais dos referidos minerais. A amostra analisada foi coletada no centro do corpo, dando-se preferência

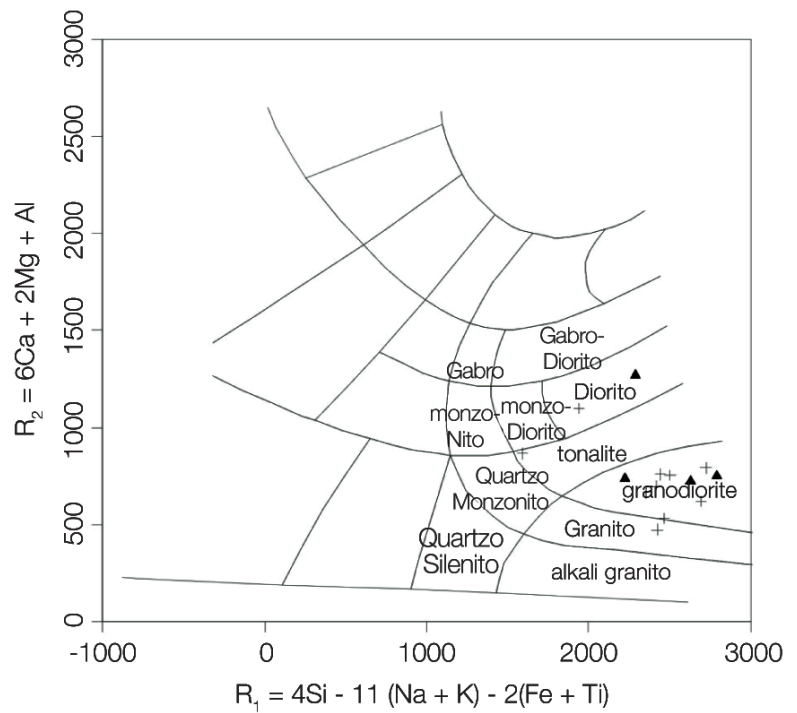

Figura 12. Diagrama discriminante $R_{1} \times R_{2}$ de De La Roche et al. (1980), com as amostras do GCS (+) e diques máficos sinplutônicos associados $(\boldsymbol{\Delta})$.

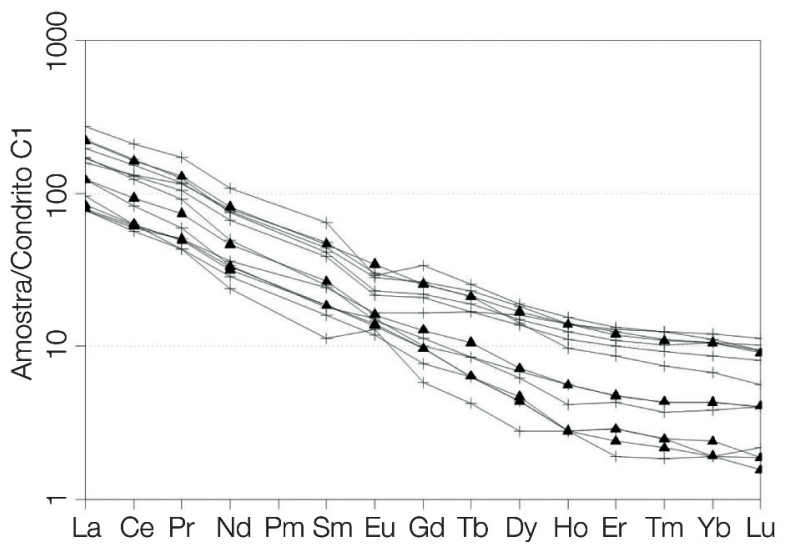

Figura 14. Padrão de ETR normalizados pelos valores condríticos C1 de Boyton (1984), com as amostras do GCS (+) e diques máficos sinplutônicos associados $(\mathbf{A})$.

aos minerais sem alteração, as Tabelas 4 e 5 contêm dados de análise química e fórmulas estruturais representativas dos anfibólios e biotitas estudados.

Nos anfibólios estudados não observou-se zonação ou texturas de desequilíbrio. São variedades cálcicas na classificação de Leake et al. (1997), e sua composição é transicional entre os campos da edenita, Fe-edenita, hastingsita e magnésio-hastingsita (Figura 16) com $\mathrm{Ca}_{\mathrm{M} 4} \geq 1,50$; $(\mathrm{Na}+\mathrm{K}$ ) ${ }_{\mathrm{A}} \geq 0,50 ; \mathrm{Ti}<0,50$, ocorrendo ainda dois grãos que plotam no campo das magnésio-hornblendas com $\mathrm{Ca}_{\mathrm{M} 4} \geq 1,50$; ( $\mathrm{Na}$ 


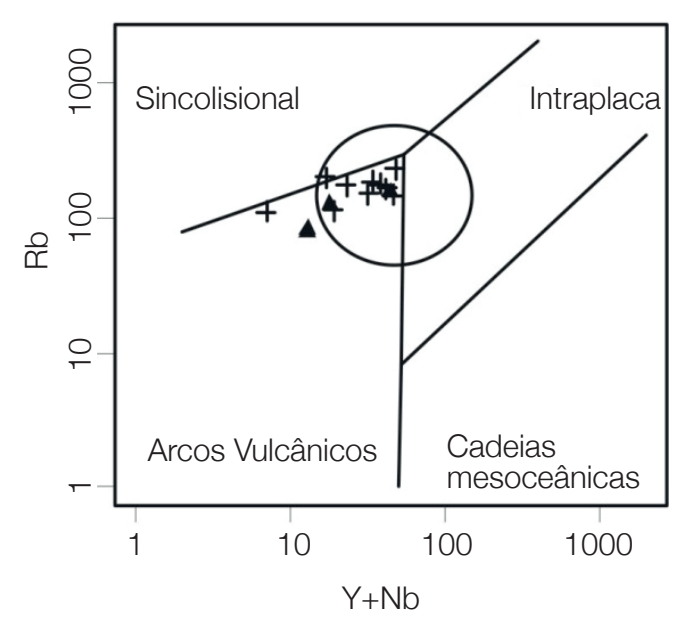

Figura 15. Diagrama discriminante de Pearce, Harris e Tindle (1984). Circulo tracejado indica campo do magmatismo pós-colisional, com as amostras do GCS (+) e diques máficos sinplutônicos associados $(\boldsymbol{\Delta})$.
$+\mathrm{K})_{\mathrm{A}}<0,50 ; \mathrm{Ca}_{\mathrm{A}}<0,50$. As razões catiônicas $\mathrm{Mg} /(\mathrm{Mg}+$ $\mathrm{Fe}^{+2)}$ e $\mathrm{FM}=\mathrm{Fe}^{+2} /\left(\mathrm{Fe}^{+2}+\mathrm{Mg}\right)$ encontram-se em torno de 0,5 , acompanhadas com valores de $\mathrm{Si}^{\mathrm{IV} \sim} 6,5$.

A utilização do teor de $\mathrm{Al}$ total $\left(\mathrm{Al}_{\mathrm{t}}\right)$ na hornblenda $(\mathrm{Hb})$ como geobarômetro, conforme originalmente concebido por Hammarstrom e Zen (1986) e reformulado por Hollister et al. (1987), com embasamento termodinâmico e dados adicionais, foi confirmada experimentalmente por Johnson e Rutherford (1989). A relação empregada neste trabalho resultou da calibração experimental obtida por Schmidt (1992). O experimento de Schmidt (1992) foi realizado em tonalitos compostos por quartzo + hornblenda + plagioclásio + ortoclásio + biotita + óxidos de Fe e Ti em intervalos de $\mathrm{P}=2,5-13$ kbar: $\mathrm{P}( \pm 0,6 \mathrm{kbar})=-3,01+4,76 \mathrm{Al}_{\mathrm{t}}$, onde $P$ é a pressão e $\mathrm{Al}_{t}$ é o alumínio total.

Tomando-se a composição das bordas dos cristais como indicativas das condições de equilíbrio com o líquido no final da cristalização, o que é corroborado pelas observações petrográficas, pode-se utilizar valores entre

Tabela 4. Composição e fórmula estrutural das biotitas do Granodiorito Cruzeiro do Sul $\left(\mathrm{FM}=\mathrm{Fe}^{+2} /\left(\mathrm{Fe}^{+2}+\mathrm{Mg}\right)\right.$.

\begin{tabular}{|c|c|c|c|c|c|c|c|c|c|c|c|c|c|c|}
\hline nos & 35 & $37 b$ & $\mathrm{f} 38$ & df25 & If26 & df33 & Df34 & df9 & df14 & 110 & ff1 & $f 6$ & ff7 & 100 \\
\hline $\mathrm{iO}_{2}$ & 863 & b,468 & 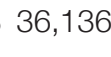 & & & ,659 & 23 & 216 & 35 & 468 & 36,468 & 05 & 4 & $t$ \\
\hline $\mathrm{O}_{2}$ & 3,288 & 3,532 & 71 & 55 & 6 & 37 & 3,952 & 4,21 & 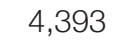 & 04 & 32 & 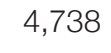 & 61 & 4,165 \\
\hline${ }_{2} \mathrm{O}_{3}$ & 14,355 & 14,583 & 14,557 & 1 & 37 & 15,411 & 14,296 & 14,441 & 14,087 & 14,359 & 583 & 14 & & 14,2 \\
\hline $\mathrm{O}$ & 22,323 & 2 & 21 & 2 & 21,066 & 19, & 22 & 20,738 & 22,14 & 22,396 & 2 & 2 & 2 & 20,785 \\
\hline $\mathrm{hO}$ & 7 & 6 & 0,389 & 0,449 & 0,396 & 0 & 9 & 11 & 6 & & 06 & 31 & 11 & \\
\hline $\mathrm{gO}$ & 4 & & & 004 & 10 & & & & & & & & & \\
\hline $\mathrm{aO}$ & & & & & & & & & & & & & & \\
\hline $\mathrm{a}_{2} \mathrm{O}$ & & & 0,084 & 094 & 035 & & & & & & & & & \\
\hline${ }_{2} \mathrm{O}$ & 9,4 & 3 & 5 & 5 & 9,721 & 9 , & 9,854 & 9,8 & & & & & & \\
\hline 20 & & & & & 85 & & & & & & & & & \\
\hline tal & 95,84 & & & 6,69 & 5,08 & & & & & & & & & \\
\hline & & & & & & & & & & & & & & \\
\hline IV & & & & & & & & & & & & & & \\
\hline $\mathrm{VI}$ & 0 & 5 & 0 & 22 & 0,204 & 0,307 & & & & & & & & \\
\hline & 0,383 & ,407 & 0,437 & 0,351 & ,384 & 0,557 & 0, & & 0 & 93 & & 0 & D2 & \\
\hline 22 & 2,894 & 2,792 & 2,745 & 2,666 & 740 & 1 & 2, & & 2,8 & & & , 71 & 679 & 2 \\
\hline In & & 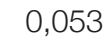 &  & 8 & , & & & & & & & & 2 & 0,0 \\
\hline Ig & & & & & & & & & & & & & & \\
\hline & & & & & & & & & & & & & & \\
\hline $\mathrm{Na}$ & 3 & 0,033 & 0,025 & 0,028 & 011 & 35 & D31 & 03 & ,032 & 3 & 33 & 033 & ,038 & 0,035 \\
\hline & 362 & 1,879 & 36 & 1,924 & 1,937 & 892 & & & 21 & 24 & 79 & 392 & 902 & 1,858 \\
\hline . & 15,731 & 15,684 & 15,653 & 15,757 & 15,714 & 15,511 & 15,693 & 15,666 & 15,636 & 15,686 & 15,684 & 15,631 & 15,646 & 15,651 \\
\hline $\mathrm{H}$ & 1,915 & 22 & 1,923 & 1,915 & 1,921 & 1,922 & 1,917 & & & & & 1,917 & 1,922 & 1,918 \\
\hline M & 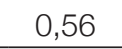 & 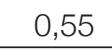 & דים & $v<$ & 0,53 & 0,0 & 0,00 & 0,00 & 0,00 & 0,0 & 0,55 & 0,54 & 0,54 & 0,53 \\
\hline
\end{tabular}


Tabela 5. Composição e fórmula estrutural dos anfibólios do Granodiorito Cruzeiro do Sul $\left(\mathrm{FM}=\mathrm{Fe}^{+2} /\left(\mathrm{Fe}^{+2}+\mathrm{Mg}\right)\right.$ e $\mathrm{MF}=\mathrm{Mg} /\left(\mathrm{Mg}+\mathrm{Fe}^{+2}\right)$.

\begin{tabular}{|c|c|c|c|c|c|c|c|c|c|c|}
\hline Amostra & Df16 & Df17 & Df18 & Df20 & Df21 & Df23 & Df27 & Df28 & Df29 & Df30 \\
\hline $\mathrm{SiO}_{2}$ & 43,737 & 43,511 & 45,161 & 42,127 & 42,233 & 44,218 & 42,097 & 43,852 & 42,564 & 42,863 \\
\hline $\mathrm{TiO}_{2}^{2}$ & 0,751 & 0,874 & 1 & 1,214 & 1,186 & 0,813 & 1,312 & 0,653 & 1,723 & 1,628 \\
\hline $\mathrm{Al}_{2} \mathrm{O}_{3}$ & 9,736 & 9,633 & 8,742 & 10,756 & 10,604 & 8,936 & 10,417 & 9,562 & 9,832 & 9,777 \\
\hline $\mathrm{FeO}^{2}$ & 20,775 & 20,715 & 20,274 & 21,864 & 21,817 & 20,749 & 21,334 & 20,838 & 20,969 & 21,204 \\
\hline $\mathrm{MnO}$ & 0,066 & 0,664 & 0,624 & 0,649 & 0,693 & 0,712 & 0,634 & 0,68 & 0,746 & 0,717 \\
\hline $\mathrm{MgO}$ & 9,153 & 9,225 & 9,579 & 8,184 & 8,121 & 9,452 & 8,309 & 8,863 & 8,334 & 8,547 \\
\hline $\mathrm{CaO}$ & 12,217 & 11,855 & 12,222 & 11,826 & 11,824 & 12,32 & 11,82 & 11,99 & 11,683 & 11,527 \\
\hline $\mathrm{Na}_{2} \mathrm{O}$ & 11,175 & 1,361 & 0,936 & 1,516 & 1,54 & 1,277 & 1,474 & 1,29 & 1,534 & 1,514 \\
\hline $\mathrm{K}_{2} \mathrm{O}^{2}$ & 1,095 & 1,135 & 1,028 & 1,42 & 1,413 & 1,008 & 1,503 & 1,21 & 1,382 & 1,359 \\
\hline Total & 99,25 & 98,97 & 99,57 & 99,56 & 99,43 & 99,49 & 98,9 & 98,94 & 98,77 & 99,14 \\
\hline TSi & 6,509 & 6,49 & 6,674 & 6,314 & 6,343 & 6,577 & 6,355 & 6,566 & 6,432 & 6,528 \\
\hline TAl & 1,491 & 1,51 & 1,326 & 1,686 & 1,647 & 1,423 & 1,645 & 1,434 & 1,568 & 1,572 \\
\hline Sum_T & 8 & 8 & 8 & 8 & 8 & 8 & 8 & 8 & 8 & 8 \\
\hline CAl & 0,216 & 0,183 & 0,195 & 0,212 & 0,219 & 0,142 & 0,207 & 0,252 & 0,181 & 0,155 \\
\hline CFe3 & 0,681 & 0,732 & 0,577 & 0,691 & 0,645 & 0,612 & 0,596 & 0,581 & 0,496 & 0,645 \\
\hline $\mathrm{CTi}$ & 0,084 & 0,098 & 0,111 & 0,137 & 0,134 & 0,091 & 0,149 & 0,074 & 0,196 & 0,184 \\
\hline $\mathrm{CMg}$ & 2,031 & 2,051 & 2,11 & 1,828 & 1,818 & 2,096 & 1,870 & 1,978 & 1,877 & 1,911 \\
\hline CFe2 & 1,905 & 1,852 & 1,929 & 2,049 & 2,096 & 1,969 & 2,097 & 2,028 & 2,154 & 2,015 \\
\hline $\mathrm{CMn}$ & 0,084 & 0,084 & 0,078 & 0,082 & 0,088 & 0,09 & 0,081 & 0,086 & 0,095 & 0,091 \\
\hline Sum_C & 5 & 5 & 5 & 5 & 5 & 5 & 5 & 5 & 5 & 5 \\
\hline $\mathrm{BCa}$ & 1,948 & 1,895 & 1,935 & 1,899 & 1,903 & 1,963 & 1,912 & 1,924 & 1,891 & 1,852 \\
\hline $\mathrm{BNa}$ & 0,052 & 0,105 & 0,065 & 0,101 & 0,097 & 0,037 & 0,088 & 0,076 & 0,109 & 0,148 \\
\hline Sum_B & 2 & 2 & 2 & 2 & 2 & 2 & 2 & 2 & 2 & 2 \\
\hline $\mathrm{ANa}$ & 0,271 & 0,288 & 0,203 & 0,339 & 0,351 & 0,332 & 0,343 & 0,298 & 0,341 & 0,292 \\
\hline AK & 0,208 & 0,216 & 0,194 & 0,271 & 0,271 & 0,191 & 0,289 & 0,231 & 0,266 & 0,26 \\
\hline Sum_A & 0,478 & 0,504 & 0,397 & 0,611 & 0,622 & 0,523 & 0,633 & 0,529 & 0,607 & 0,552 \\
\hline Sum_cat & 15,478 & 15,504 & 15,397 & 15,611 & 15,622 & 15,523 & 15,633 & 15,529 & 15,607 & 15,552 \\
\hline Sum_oxi & 23 & 23 & 23 & 23 & 23 & 23 & 23 & 23 & 23 & 23 \\
\hline MF & 0,52 & 0,53 & 0,52 & 0,47 & 0,46 & 0,52 & 0,47 & 0,49 & 0,47 & 0,49 \\
\hline FM & 0,48 & 0,47 & 0,48 & 0,53 & 0,54 & 0,48 & 0,53 & 0,51 & 0,53 & 0,51 \\
\hline Alt & 1,71 & 1,69 & 1,52 & 1,52 & 1,88 & 1,57 & 1,85 & 1,69 & 1,75 & 1,73 \\
\hline
\end{tabular}

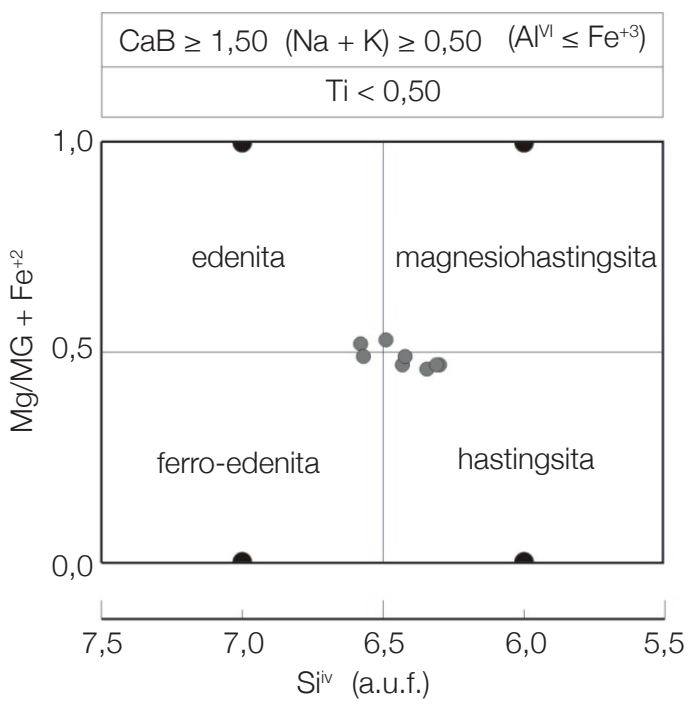

Figura 16. Classificação dos anfibólios do GCS de acordo com a nomenclatura de Leake et al. (1997).
1,57 a 1,75 auf de $\mathrm{Al}_{\mathrm{t}}$, como parâmetro para avaliar a pressão total próximo às condições da solidus do granodiorito. Evidência adicional da condição de equilíbrio atingida nas bordas dos cristais de anfibólio do GCS é representada pela relação entre a razão $\mathrm{Fe} /(\mathrm{Fe}+\mathrm{Mg})(\mathrm{FM})$ próxima de 1:1 (Tabelas 4 e 5) de anfibólio e biotita coexistentes.

A aplicação do geobarômetro $\mathrm{Al}_{\mathrm{t}}-\mathrm{Hb}$, segundo a formulação de Schmidt (1992), à composição das bordas de cristais de anfibólio do GCS resulta em valores em torno de 4,3 a 5,3 Kbar, e aplicando esse valor na equação T(b), proposta por Holland e Blundy (1994), que utiliza a composição do par hornblenda-plagioclásio para determinar a temperatura do sistema próximo da curva solidus, obtêm-se temperaturas entre 719 e $761^{\circ} \mathrm{C}$. O emprego deste geotermômetro se restringe a temperaturas entre 500 e $900^{\circ} \mathrm{C}$, composição de plagioclásio com $0,1<\mathrm{XAn}<0,9$, anfibólio com XNa $>0,03$ auf, Alvi $<1,8$ auf e Siiv entre 6,0 e 7,7 auf, com ou sem quartzo, como pode se observar na Equação 1: 


$$
\mathrm{T}[ \pm 313 \mathrm{~K}]=\frac{81,44-33,6 \mathrm{X}_{\mathrm{Na}}^{\mathrm{M} 4}-(66,88-2,92 \mathrm{P}[\mathrm{kbar}]) \mathrm{X}_{\mathrm{Al}}^{\mathrm{M} 2}+78,5 \mathrm{X}_{\mathrm{Al}}^{\mathrm{T1}}+9,4 \mathrm{X}_{\mathrm{Na}}^{\mathrm{A}}}{0,0721-0,0083144 \ln \left(\frac{27 \mathrm{X}_{\mathrm{Na}}^{\mathrm{M} 4} X_{\mathrm{Si}}^{\mathrm{T1}} X_{\mathrm{Al}}^{\mathrm{T1}} X_{\mathrm{An}}^{\mathrm{Plag}}}{64 \mathrm{X}_{\mathrm{Ca}}^{\mathrm{M} 4} X^{\top 1} X_{\mathrm{Al}}^{\top 1} X_{\mathrm{Ab}}^{\mathrm{Plag}}}\right)}
$$

onde:

$\mathrm{X}_{\mathrm{ab}}$ é a fração molar de albita no plagioclásio e $\mathrm{X}^{\mathrm{T} 1, \mathrm{M} 4, \mathrm{M} 2 \ldots}$ são os sítios catiônicos dos respectivos elementos, sendo T dada em Kelvin e P em Kbar.

O zircão é uma das fases mais precoces do magma. A utilização do geotermômetro $\mathrm{Zr}$ fornece a temperatura próxima da líquidus, suas concentrações nas amostras do GCS situam se em torno de 240 ppm (em média), aproximando-se dos teores de saturação em temperaturas da ordem de $785^{\circ} \mathrm{C}$, conforme os dados de Watson e Harrison (1983) para sistemas com alcalinidade similar. No caso estudado, esta temperatura pode representar valores menores do que o normal, devido à contaminação crustal por rochas com teores mais baixos de $\mathrm{Zr}$.

A biotita possui pleocroísmo que varia em tons de castanho a castanho avermelhado, com características petrográficas muito semelhantes, exceto por agregados muito finos de titanita xenomórfica na borda de alguns grãos, sugerindo-se a perda de titânio, provavelmente por reequilíbrio subsolidus das biotitas primárias. Essas biotitas com perda de Ti foram identificadas no diagrama Ti $\mathrm{x} \mathrm{Al}{ }^{\mathrm{VI}}$, apresentado na Figura 17, no qual nota-se também o aumento do $\mathrm{Al}^{\mathrm{VI}}$ em função da diminuição do Ti, enquanto a razão FM comparada com os valores de Ti permanece constante na ordem de 0,53 a 0,56 (Tabela 5).

No diagrama idealizado por Nachitt et al. (1985), a biotita do GCS tem comportamento geral compatível com o de granitoides subalcalinos ferrosos (Figura 18). A biotita do Granito Estaleiro (Bitencourt, 1996), também de afinidade shoshonítica e sin-transcorrente, mostra composição com teores de Al total e Mg mais elevados. A biotita do GCS é composicionalmente semelhante à granitoides de afinidade shoshonítica intraplaca, como os da Associação Shoshonítica de Lavras do Sul (Nardi, 1984; Barros e Nardi, 1994) ou do Complexo de Rio Espinharas (Campos, Neiva, Nardi, 2000). A biotita presente em típicos granitoides de afinidade shoshonítica plotam no campo subalcalino magnesiano do diagrama de Nachit et al. (1985), como é bem ilustrado pela biotita do Ballons Massif, referida por Stussi e Cuney (1996), e pelas biotitas do Monzograntio Santo Antônio, de Barros e Nardi (1994) (Figura 18).

\section{DISCUSSÃO}

O granitoide exposto na área de estudo, juntamente com os Granitoides Arroio Divisa e Sanga do Areal, podem

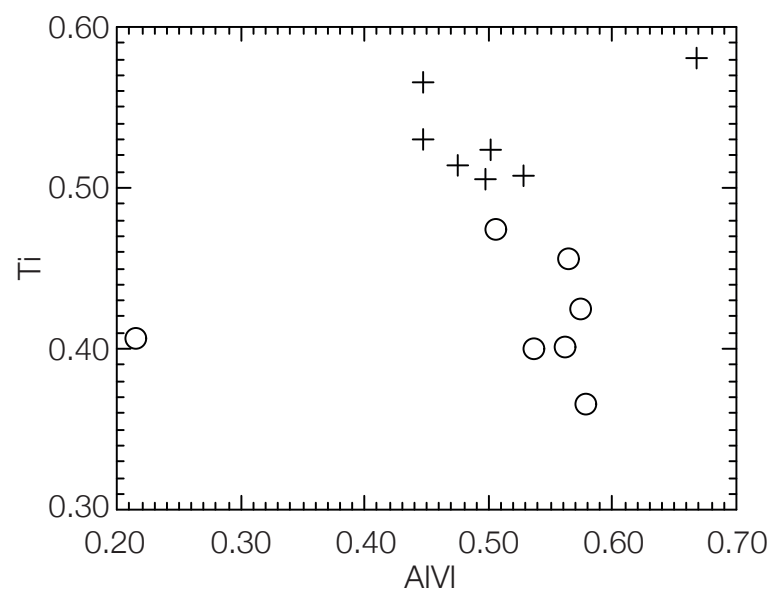

Figura 17. Diagrama Ti x AIVI das biotitas primárias (+) e biotitas com reequilíbrio subsolidus (o).

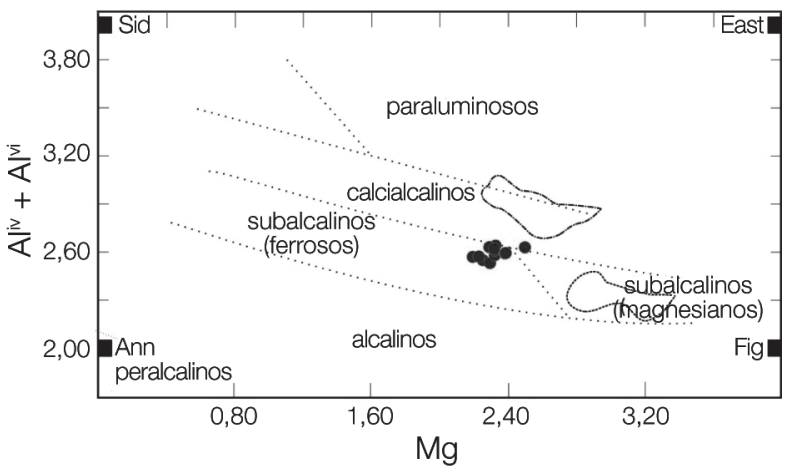

Figura 18. Biotitas do GCS (pontos em preto), do Granito Estaleiro (tracejado) e do Monzogranito Santo Antônio discriminadas (pontilhado) no diagrama $\mathrm{Al}_{\mathrm{t}} \times \mathrm{Mg}$; com os campos delimitados por Nachitt et al. (1985).

ser considerados como constituintes de uma associação petrotectônica intrusiva no Complexo Arroio dos Ratos, relacionada a um evento transcorrente do CCSB. O sentido de movimento sinistral desta zona transcorrente é confirmado por diversos indicadores cinemáticos de escala meso e microscópica, e microestruturas desenvolvidas sobre os feldspatos indicam temperaturas de deformação na ordem de 550 a $600^{\circ} \mathrm{C}$ compatíveis com as da fácies anfibolito.

O fato de a foliação magmática do GCS evoluir para uma milonítica com mesma direção e igual mergulho (em 
alto ângulo), assim como a ocorrência de diversas estruturas de deformação, em injeções leucocráticas que cortam o GCS, geradas sob o mesmo campo de tensão que gerou a foliação milonítica, indica somente uma fase de deformação dúctil nesta unidade. $\mathrm{O}$ alto ângulo da foliação milonítica contendo lineação de estiramento de baixa obliquidade indica a cinemática transcorrente da zona de cisalhamento.

O GCS preserva características primárias que podem ser vistas em macro e microescala na forma de cristais de feldspatos com formas ígneas preservando faces retas e maclas bem formadas, principalmente no centro do corpo. Cristais de zircão zonados, com formas alongadas e bipiramidados, também sugerem características magmáticas.

A afinidade shoshonítica do magmatismo constituinte do GCS é revelada pelos altos teores de Sr e pelo comportamento linear e homogêneo dos ETR e abundância dos ETRL em relação aos ETRP. Os padrões de elementos traço com enriquecimento em $\mathrm{Ba}$ e $\mathrm{Rb}$, e o empobrecimento dos HFS em relação aos LILE e seu caráter metaluminoso também são importantes características das rochas de afinidade shoshonítica. A razão FM tem valores na ordem de 0,5 para as biotitas e anfibólios, e de 0,7 na rocha total. Essas razões mais baixas na biotita e no anfibólio do que na rocha total poderiam sugerir a cristalização de óxidos de $\mathrm{Ti}$ e $\mathrm{Fe}$, concomitante à cristalização das biotitas e anfibólios.

$\mathrm{O}$ fato de ocorrer uma variação das temperaturas de saturação do $\mathrm{Zr}$ (Tsat. Zr) entre 750 até $850^{\circ} \mathrm{C}$ em diversos pontos do corpo e não estarem vinculadas à localização de amostragem não permite relacioná-las com a quantidade de deformação sofrida pelo corpo, ou seja, as Tsat. Zr não seguem um padrão em um perfil do centro do corpo para as bordas (zonas de alta deformação).

A contaminação dos magmas parentais shoshoníticos do GCS por fusões crustais é compatível com: caráter levemente peraluminoso e subalcalino do GCS em comparação com as rochas shoshoníticas sem contaminação na crosta, por exemplo, a Associação Shoshonítica Lavras do Sul; a contaminação crustal causou uma diminuição dos conteúdos de álcalis $\left(\mathrm{Na}_{2} \mathrm{O}\right.$ e $\left.\mathrm{k}_{2} \mathrm{O}\right)$, o que, além de tornar o magma subalcalino, causou o afastamento das rochas plotadas no diagrama R1R2 (Figura 12) dos campos monzoníticos e quartzo-monzoníticos, típicos do magmatismo shoshonítico; por fim, a zona de cisalhamento transcorrente em que o GCS está inserido também pode ter facilitado os processos de contaminação e assimilação crustal.

\section{CONCLUSÕES}

O granitoide em estudo apresenta-se como um corpo alongado segundo a direção ENE, posicionado ao longo de uma zona de cisalhamento transcorrente sinistral com mesma direção. A forma alongada do corpo paralelamente à zona de transcorrência, a concordância e a progressão da foliação magmática em relação à milonítica, ambas em alto ângulo de mergulho e paralelas aos limites da intrusão, são evidências estruturais de seu caráter sintectônico. Por outro lado, a ausência de foliação metamórfica retrabalhada pela milonítica permite concluir que o GCS registra apenas uma fase de deformação, que teria ocorrido durante seu posicionamento. Desta forma, entende-se que esta zona de cisalhamento ENE subvertical possibilitou a abertura de espaço para a entrada deste magmatismo, deformando o mesmo simultaneamente, e conclui-se que o GCS não tem relação com o evento transversal de direção EW e baixo ângulo de mergulho, responsável pela deformação do Complexo Arroio dos Ratos referido por Fernandes et al. (1992), mas está vinculado ao evento posterior de transcorrência da Zona de Cisalhamento Dorsal de Canguçu.

Devido à baixa viscosidade relativa dos magmas parcialmente cristalizados e às altas temperaturas, a intrusão posterior dos GAD e GSA contribui com o calor e modifica a reologia da crosta, facilitando a atuação dos mecanismos de deformação nestas litologias.

O GQ $(631 \pm 6) \mathrm{U}-\mathrm{Pb}$ (TIMS), datado por Koester et al. (2001), é colocado por diversos autores (Koester et al.,1997; Fernandes et al., 1993; Hartmann, Chemale, Philipp, 2007) como fazendo parte dos estágios iniciais de movimentação das zonas de alto ângulo de caráter dúctil e sentido de movimento sinistral, que compõem o sistema de zonas da ZCTDC. Assim, pode-se interpretar que a cinemática transcorrente sinistral e a alta deformação observada na zona de cisalhamento estudada são compatíveis com a da ZCTDC, podendo representar uma estrutura precoce do mesmo sistema, uma ramificação da ZCTDC ou a própria.

Novos dados de Geocronologia U-Pb em zircão admitem idades de cristalização em torno de 630 Ma para o GCS, reforçando a ideia de uma estrutura precoce.

As condições de $\mathrm{P}$ e $\mathrm{T}$, calculadas a partir do geobarômetro Alt-Hb e de termobarometria do par $\mathrm{Plg}-\mathrm{Hb}$, são estimadas em cerca de 4,3 a 5,3 kbars e temperaturas de cristalização na ordem de 719 a $761^{\circ} \mathrm{C}$. Esses valores demonstraram-se coerentes quando recalculados pelo cálculo de termobarometria do par Plg-Hb, de Anderson (1996), obtendo valores em torno de $4 \mathrm{Kbar}$ e $750^{\circ} \mathrm{C}$, porém, optou-se por utilizar equações de geotermobarometria já consagradas na literatura. Supondo-se gradiente normal de pressão, estas condições equivalem a cerca de 10 a $15 \mathrm{~km}$ de profundidade, compatíveis com uma temperatura da ordem de 300 a $450^{\circ} \mathrm{C}$ nas encaixantes.

As temperaturas de cristalização em torno de 719 a $761{ }^{\circ} \mathrm{C}$ são similares às encontradas por Koester (1995) para o GQ entre 700 e $750^{\circ} \mathrm{C}$, fato que também permite 
correlacionar estas duas intrusões sintectônicas à mesma descontinuidade.

Tendo em vista que o GSA é o mais recente inserido na zona de cisalhamento estudada e que possui o mesmo grau de deformação dos GAD e do GCS, sua idade de cristalização pode indicar um estágio próximo do termino de ativação da zona.

Esta zona de cisalhamento ENE transcorrente tem escala regional, podendo atingir quase $30 \mathrm{~km}$ de extensão, sendo responsável pelo posicionamento de um volume de magmas extremamente grande e possivelmente por parte da contaminação crustal atribuída ao GCS. Sua caracterização é de fundamental importância para o melhor entendimento da evolução deste sistema de diversas zonas de transcorrência, que compõe o CCSB e a ZCTDC.

Comparado aos granitoides de afinidade shoshonítica, que não são sintranscorrentes, por exemplo, os da Associação Shoshonítica Lavras do Sul, as rochas do GCS são mais peraluminosas, relativamente empobrecidas em $\mathrm{Sr}$ e subalcalinas, isto é, têm teores mais baixos de $\mathrm{Na}_{2} \mathrm{O}$ e $\mathrm{K}_{2} \mathrm{O}$ do que os granitoides shoshoníticos. Este aumento da peraluminosidade pode estar relacionado, ao menos parcialmente, com o processo de sericitização visto nos feldspatos do GCS. As diferenças composicionais observadas entre o GCS e os granitoides não relacionados com transcorrência podem ser explicadas pela contaminação dos magmas parentais shoshoníticos com fusões crustais contemporâneas ao seu posicionamento e cristalização, conforme sugerido por Nardi e Bitencourt (2009) para granitoides do tipo A.

Segundo Knijnik et al. (2010), a presença de zircões herdados corrobora com a ideia de contaminação crustal durante a ascensão do GCS.

A presença de corpos máficos associados pode indicar profundidades dos níveis litosféricos da zona de cisalhamento, atingindo e fundindo o manto. Esses corpos máficos possuem comportamento dos ETR e dos elementos traços muito similares aos das rochas do GCS (Figuras 13 a 15), sugerindo sua cogeneticidade, assim como os valores semelhantes de $\mathrm{Ba}$ e $\mathrm{Sr}$ para as duas litologias também sugerem magmas cogenéticos.

As características composicionais são consistentes com o caráter pós-colisional do magmatismo e o empobrecimento de $\mathrm{Nb}$ em relação aos ETRL, bem como o enriquecimento em ETRL e LILE é típico de magmas relacionados a fontes metassomatizadas durante subducção prévia (Kelemen, Shim, Dunn, 1993).

A idade de $634 \mathrm{Ma}$ é mais antiga do que a das rochas de afinidade shoshonítica descritas no Sul do Brasil (610 a $590 \mathrm{Ma}$ ). Isto indica que fontes mantélicas produtoras de magmas shoshoníticos, que foram importantes entre
610 a $590 \mathrm{Ma}$, tiveram ativações precoces no início do estabelecimento do Cinturão de Cisalhamento SulBrasileiro, imediatamente após a colisão principal do ciclo Brasiliano-Pan-africano.

\section{REFERÊNCIAS}

ANDERSON, J. L. Status of thermobarometry in granitic batholiths. Transactions of the Royal Society of Edinburgh, Earth Sciences, v. 87, p. 125-138, 1996.

ALMEIDA, F. F. M.; HASUI, Y.; BRITO NEVES, B. B.; FUCK, R.A. Províncias Estruturais Brasileiras. In: Simpósio de Geologia do Nordeste, 1977. Anais... Campina Grande: SBG, 1977. p. 363-391.

BARROS, C. E.; NARDI, L. V. S. O Maciço Granítico Santo Antônio, RS: Magmatismo Neoproterozoico de Afinidade Shoshonítica. Anais da Academia Brasileira de Ciência, v. 66, n. 4, p. 441-465, 1994.

BITENCOURT, M. F. Granitóides Sintectônicos da Região de Porto Belo, SC: uma abordagem petrológica e estrutural do magmatismo em zonas de cisalhamento. 310p, 1996. Tese (Pós-Graduação em Geociências) Universidade Federal do Rio Grande do Sul - UFRGS, Brasil.

BITENCOURT, M. F.; NARDI, L. V. S. Tectonic setting and sources of magmatism related to the Southern Brazilian Shear Belt. Revista Brasileira de Geociencias, v. 30, p. 184-187, 2000.

BITENCOURT, M. F.; NARDI, L. V. S. Late to postcollisional Brasiliano granitic magmatism in southernmost Brazil. Anais da Academia Brasileira de Ciências, v. 65, p. 3-16, Suplemento 1, 1993.

BOYNTON, W. V. Cosmochemistry of the rare earth elements: meteorite studies. In: Henderson P (eds) Rare Earth Element Geochemistry. Elsevier, Amsterdam, p. 63-114, 1984.

CAMPOS, T. F.; NEIVA, A. M.; NARDI, L. V. S. Geochemistry of the hybrid complex and their minerals from Rio Espinharas Pluton, Northeastern Brazil. Lithos, v. 64, p. 131-153, 2000.

CENTENO, P. A. Geologia dos Granitóides Sanga do Areal, intrusivos no Complexo Arroio dos Ratos, na Região de Quitéria - Serra do Erval, RS. Trabalho de Conclusão de Curso (Graduação em Geologia) - Universidade Federal do Rio Grande do Sul, 2008. 
DE LA ROCHE, H.; LETERRIER, J.; GRANDCLAUDE, P.; MARCHAL, M. A classification of volcanic and plutonic rocks using R1R2-diagram and major element analyses - its relationships with current nomenclature. Chemical Geology, v. 29, p.183-210, 1980.

FERNANDES, L. A. D.; TOMMASI, A.; PORCHER, C. C. Esboço estrutural de parte do Batólito Pelotas - região de Quitéria-Capivarita. Acta Geológica Leopoldinense, v. 13, p. 117-138, 1990.

FERNANDES, L. A. D. MENEGAT, R.; COSTA, A. F. U.; KOESTER, E.; PORCHER, C. C.; TOMMASI, A.; KRAEMER, G.; RAMGRAB, E.; CAMOZZATO, E. Evolução Tectônica do Cinturão Dom Feliciano no Escudo Sul-Rio-grandense: Parte I - Uma contribuição a partir do registro geológico. Revista Brasileira de Geociências, São Paulo, v. 25, p. 351-374, 1995.

FERNANDES, L. A. D.; MENEGAT, R.; COSTA, A. F. U.; KOESTER, E.; PORCHER, C. C.; TOMMASI, A.; KRAEMER, G.; RAMGRAB, G. E.; CAMOZZATO, E. 1988. Mapa geológico de parte das folhas de Quitéria e Várzea do Capivarita, RS. Universidade Federal do Rio Grande do Sul. Série Mapas. Mapa 14. p. 1-7, 1 mapa preto e branco.

FERNANDES, L. A. D.; TOMMASI, A.; VAUCHEZ, A.; PORCHER, C. C.; MENEGAT, R.; KOESTER, E. Zona de Cisalhamento Transcorrente Dorsal de Canguçu: Caracterização e Importância na Compartimentação Tectônica do Cinturão Dom Feliciano. Revista Brasileira de Geociências, v. 23, n. 20, p. 1-10, 1993.

FLORISBAL, L. M.; BITENCOURT, M. F.; NARDI, L. V. S.; CONCEIÇÃO, R. V. Early post-collisional granitic and coeval mafic magmatism of medium to high-K tholeiitic affinity within the Neoproterozoic Southern Brazilian Shear Belt. Precambrian Research, v. 175, n. 1-2, p. 135148, 2007.

FONTANA, E. Granitóides Arroio Divisa: considerações estratigráficas e petrogenéticas. Trabalho de Conclusão de Curso 2008 (Graduação em Geologia) - Universidade Federal do Rio Grande do Sul, Porto Alegre, 2008.

FRANTZ, J. C.; MCNAUGHTON, N. J.; MARQUES, J. C.; HARTMANN, L. A.; BOTELHO, N. F.; CARAVACA, G. SHRIMP U-Pb Zircon ages of granitoids from southernmost Brazil: constraints on the temporal evolution of the dorsal de canguçu transcurrent shear zone and the eastern dom Feliciano belt. Short Papers. In: IV South American Symposium on Isotope Geology Salvador BA, 2003.
GREGORY, T. R. Caracterização Estrutural e Petrológica do Magmatismo Precoce do Complexo Gnáissico Arroio dos Ratos. p. 66. Graduação em Geologia - Universidade Federal do Rio Grande do Sul, Porto Alegre, 2007.

GREGORY, T.R.; BITENCOURT, M. F.; NARDIL, V. S. Caracterização estrutural e petrológica de metatonalitos e metadioritos do Complexo Arroio dos ratos na sua seção-tipo, região de Quitéria, RS., pesquisas, 2011 (No prelo).

HAMMARSTROM, J. M; ZEN, E. A. Aluminium in hornblende: an empirical igneous geobarometer. American Mineralogist, v. 71, p. 1297-1313, 1986.

HARRIS, N. W. B.; PEARCE, J. A.; TINDLE A. G. Geochemical characteristics of collision-zone magmatism. In: COWARD, M.P.; RIES, A.C. Collision tectonics. Geological Society of London, Special Paper, v. 19, p. 115-158, 1986.

HARTMANN, L. A.; CHEMALE, F. J.; PHILIPP, R. P. Evolução Geotectônica do Rio Grande do Sul no PréCambriano. In: IANUZZI, R.; FRANTZ, J.C. (Org.). 50 Anos de Geologia. Instituto de Geociências. Contribuições. Porto Alegre: Comunicação e Identidade, v. 2, p. 97-123, 2007.

HARTMANN, L. A.; NARDI, L. V. S.; FORMOSO, M. L. L.; REMUS, M. V. D.; LIMA, E. F.; MEXIAS, A. S. Magmatism and metallogeny in the crustal evolution of Rio Grande do Sul shield, Brazil. Pesquisas em Geociências (UFRGS), Porto Alegre, v. 26, n. 2, p. 73-92, 1999.

HOLLAND, T.; BLUNDY, J. Non-ideal interactions in calcic amphiboles and their bearing on amphiboleplagioclase thermometry. Contributions to Mineralogy and Petrology, v. 116, p. 433-447, 1994.

HOLLISTER, L. S.; GRISSOM, G. C.; PETERS, E. K.; STOWELL, H. H.; SISSON, V. B. Confirmation of the empirical correlation of $\mathrm{Al}$ in hornblende with pressure of solidification of calc-alkaline plutons. American Mineralogist, v. 72, p. 231-239, 1987.

JENSEN, L. S. A New Cation Plot for Classifying Subalkalic Volcanic Rocks. Ontario Geological Survey Miscellaneous Paper, p. 66, 1976.

JOHNSON, M. C.; RUTHERFORD, M. J. Experimental calibration of the aluminum-in-hornblende geobarometer with application to Long Valley caldera (California) volcanic rocks. Geology, v. 17, p. 837-841, 1989. 
KELEMEN, P. B.; SHIM, N.; DUNN, T. Relative depletion of niobium in some arc magmas and the continental crust: partitioning of $\mathrm{K}, \mathrm{Nb}$, La and Ce during melt/rock reaction in the upper mantle. Earth and Planetary Science Letters, v. 120, p. 111-134, 1993.

KNIJNIK, D. B. Posicionamento estrutural, caracterização petrográfica e geoquímica do Granodiorito Cruzeiro do Sul e rochas máficas associadas, região de Quitéria, RS. Trabalho de Conclusão de Curso (Graduação em Geologia) Universidade Federal do Rio Grande do Sul, Porto Alegre, 2008.

KNIJNIK, D. B. U-Pb (SHIRIMP) Zircon geochronology of the Cruzeiro do Sul granodiorite post-collisional shoshonitic magmatismo from southern Brazil. In: VII - SSAGI SOUTH AMERICAN SYMPOSIUM ON ISOTOPE GEOLOGY. Brasília, 2010.

KOESTER, E. Evolução geológica do magmatismo sintectônico à Zona de Cisalhamento Transcorrente Dorsal de Canguçu, região de Encruzilhada do Sul, RS. 240 p. (Dissertação de Mestrado em Geociências) - Instituto de Geociências, Universidade Federal do Rio Grande do Sul, Porto Alegre, 1995.

KOESTER, E.; SOLIANI JR., E.; FERNANDES, L. A. D.; KRAEMER, G.; TOMMASI, A. Geocronologia Rb/Sr e K/ Ar dos granitóides sintectônicos à Zona de Cisalhamento Transcorrente Dorsal de Canguçu na região de Encruzilhada do Sul (RS). Revista Pesquisas, v. 24, n. 1/2, p. 67-77, 1997.

KOESTER, E.; SOLIANI JR., E.; LEITE, J. A. D.; HARTMANN, L. A.; FERNANDES, L. A. D.; MCNAUGHTON, N. J.; SANTOS, J. O. S.; OLIVEIRA, L. D. Shrimp U-Pb age for the emplacement of the Santana Granite and reactivation of the Porto Alegre Suture, southern Brazil. Journal of South American Earth Sciences, v. 14, p. 91-99, 2001.

LE BAS, M. J.; LE MAITRE, R. W.; STRECKEISEN, A.; ZANETTIN, B. A chemical classification of volcanic rocks based on the total alkali-silica diagram. Journal of Petrology, v. 27, p. 745-750, 1986.

LE MAITRE, R. W. Igneous Rocks: a classification and glossary of terms. Cambridge University Press, Cambridge. 236p, 2002.

LEAKE, B. E.; WOOLEY, A. R.; ARPS, C. E. S.; BIRCH, W. D.; GILBERT, M. C.; GRICE, J. D.; HAWTHOENE, F. C.; KATTO, A.; KISCH, H. J.; KRIVOVICHEV, V. G.; LINTHOUT, K.; LAIRD, J.; MANDARINO, J. A.; MARESH, W. V.; NICKEL, E. H.; ROCK, N. M. S.;
SCHUMACHER, J. C.; SMITH, D. C.; STEPHENSON, N. C. N.; UNGARETTI, L.; WITTAKER, E. J. W.; YOUZHI, G. Nomenclature of amphiboles: report of the subcommittee on amphiboles of the international mineralogical association, commission on new minerals names, American Mineralogist, v. 82, p. 1019-1037, 1997.

LIÉGEOIS, J. P.; NAVEZ, J.; HERTOGEN, J.; BLACK R. Contrasting origin of post-collisional high-K calcalkaline and shoshonitic versus alkaline and peralkaline granitoids. The use of sliding normalization. Lithos, v. 45, p. $1-28,1998$.

LIMA, E. F.; NARDI, L. V. S. The Lavras do Sul Shoshonitic Association: implications for the origin and evolution of Neoproterozoic shoshonitic magmatism in southernmost Brazil. Journal of South American Earth Sciences, v. 11, p. 67-77, 1998.

MORRISON, G. W. Characteristics and tectonic setting of the shoshonite rocks association. Lithos, v. 13 p. 97-108, 1980.

NACHITT, H.; RAZAFIMAHEFA, N.; STUSSI, J. M.; CARRON, J. P. Composition chimique dês biotites et typologie magmatique des granitoides. Comptes Rendus de l'Académie des Sciences, Paris, Série II, n. 11, p. 813818, 1985.

NARDI, L. V. S. Geochemistry and petrology of the Lavras Granite Complex, RS, Brazil. Londres. 268p. Tese de Doutorado em Geologia - London University, 1984.

NARDI, L. V. S.; BITENCOURT, M. F. A-type granitic rocks in post-collisional settings in southernmost Brazil: their classification and relationship with tectonics and magmatic series. Canadian Mineralogist, v. 47, n. 6, p. 1493-1503, 2009.

NARDI, L. V. S.; BITENCOURT, M. F. Magmatismo Granítico e Evolução Crustal no Sul do Brasil. In: IANUZZI, R.; FRANTZ, J.C. (Org.). 50 Anos de Geologia. Instituto de Geociências. Contribuições. Porto Alegre: Editora Comunicação e Identidade, v. 2, p. 125-139, 2007.

PEARCE, J. A.; HARRIS, N. B. W.; TINDLE, A. G. Trace element discrimination diagrams for the tectonic interpretation of granitic rocks. Journal of Petrology, v. 25, p. 956-983, 1984.

RICHARD, L. R. Minpet Software. Mineralogical and Petrological data processing system. Versão 2.02. Copyright (1988-1995), 1995. 
SCHMIDT, M. W. Amphibole composition in tonalite as a function of pressure:an experimental calibration of the Al-in-hornblende barometer. Contributions to Mineralogy and Petrology, v. 110, p. 304-310, 1992.

SHAND, S. J. Eruptive Rocks. Their Genesis, Composition, Classification, and Their Relation to OreDeposits with a Chapter on Meteorite. New York: John Wiley \& Sons, 1943.

SIBSON, R. H. Fault rocks and fault mechanisms. Journal of the Geological Society, v. 3, p. 191-213, 1977.

SOLIANI, JR., E. Os dados geocronológicos do Escudo Sul. Rio-Grandense e suas implicações de ordem geotectônica. São Paulo. 425p. Tese (Doutorado) - Instituto de Geociências, Universidade de São Paulo, 1986.

STRECKEISEN, A. To each plutonic rock its proper name. Earth-Sciences Review, v. 12, p. 1-33, 1976.
STUSSI, J. M.; CUNEY, M. Nature of biotites from alkaline,calc-alkaline and peraluminous magmas by Abdel-Fattah M. Abdel-Rahman: A Comment. Journal of Petrology, v. 37, n. 5, p. 1025-1029, 1996.

UFRGS. Mapeamento Geológico de parte das folhas Quitéria SH22-Y-B-I-4 (MI2985/4) e Serra do Erval - SH 22-Y-B-II-3 (MI2986/3), RS. Porto Alegre. 1 vol., 2 mapas. Curso de Geologia. Instituto de Geociências, Universidade Federal do Rio Grande do Sul, 2007.

UFRGS. Mapeamento Geológico de parte da Folha Quitéria SH22-Y-B-I-4 (MI2985/4), RS. Porto Alegre. 1 vol., 2 mapas. Curso de Geologia - Instituto de Geociências, Universidade Federal do Rio Grande do Sul, 2006.

WATSON, E. B.; HARRISON, T. M. Zircon saturation revisited: temperature and composition, effects in a variety of crustal magma types. Earth and Planetary Sciences Letters, v. 64, p. 295-30, 1983. 